https://doi.org/10.31426/ijamsr.2018.1.10.1012

\title{
Weather Based Forewarning of Pest and Disease: An Important Adaptation Strategies Under The Impact of Climate Change Scenario: A Brief Review
}

\author{
J. Singh ${ }^{1}$, D.K.Das ${ }^{2}$, S.Vennila ${ }^{3}$ and K.S. Rawat ${ }^{4}$ \\ ${ }^{I}$ Central Tasar Research and Training Institute, Ranchi, India \\ 2Division of Agricultural physics, Indian Agricultural Research Institute, New Delhi, India. \\ 3 National Centre for Integrated Pest Management, L.B.S, Building, New Delhi, India. \\ 4Centre for Remote Sensing and Geo-Informatics, Sathyabama Institute of Science and Technology, Chennai, India \\ Email: jitendrasingh.iari@gmail.com
}

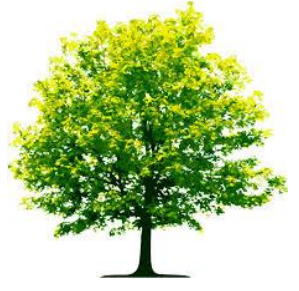

Keywords:

Forewarning,

modeling, pest, disease, IASRI, IMD, NCIPM, surveillance etc.

\begin{abstract}
A B S T RA C T
The intergovernmental panel on climate change predicts the current emission scenario; the global mean temperature would rise between 0.9 and $3.5^{\circ C}$ by the year 2100. It may be affects pest, disease and plants and is likely to make plants more vulnerable to infectious disease, which cause reduces the yield of agricultural crop. Some other problem is also generated due to climate change such as new pest and disease complexes may arise and some pest and diseases may cease to be economically important if warming causes a pole ward shift of agro climatic zones and host plant migrate into new regions. Disease triangle is a conceptual model that shows the interactions between the weather, host and pathogen. These three components are essential for appearance of crop insect pest, disease and favorable of weather condition, crop stage and occurrences of pathogen (all three conditions) are responsible its severity. Pest/disease infestation in crops is highly influenced by meteorological parameters such as mean maximum temperature, mean minimum temperature, mean temperature, mean morning relative humidity, mean evening relative humidity, mean relative humidity, total rainfall, mean wind speed and mean bright sunshine hour etc.
\end{abstract}

Citation: J. Singh, D.K.Das, S.Vennila, K.S. Rawat (2018). Weather Based Forewarning of Pest and Disease: An Important Adaptation Strategies Under the Impact of Climate Change Scenario: A Brief Review. International Journal of Advanced Multidisciplinary Scientific Research (IJAMSR ) ISSN:2581-4281 Vol 1, Issue 10, December, 2018, \#Art.1012, pp 6-21 


\section{International Journal of Advanced Multidisciplinary Scientific Research (IJAMSR) ISSN:2581-4281}

\section{Introduction}

On the basis of weather and pest interaction (iterative approach) some scientist and institute are developed weather based prediction rule and find congenial weather for outbreak and intensities of crop pest and diseases. The weather based forewarning and modeling of pest and disease for early warning of pest/disease outbreak/infestation may provide appropriate tools for investigating and predicting pest/disease status (high, moderate and low). Pest surveillance and forewarning of insect pest and disease are the key component of crop protection strategies under the impact of climate change scenario. It reduces the cost of production by optimizing the timing and frequency of application of pest management measures and ensures operator, consumer and environmental safety by reducing chemical usage. Some institute such as Indian Agricultural Statistical Research Institute (IASRI), India Meteorological Department (IMD) and National Centre for Integrated Pest Management (NCIPM) plays an important role for forewarning of insect pest and disease and communicate it farmer level. The main focus of the current review paper is to find out the scenario of crop pest under climate change and congenial weather condition for the outbreak and intensities of crop pest and diseases.

Climate is a key driver of most insect-pests, disease, and a changing climate will alter the distribution, abundance and management of endemic pests and disease (Chakraborty 2005). According to IPCC's latest report, global mean temperature would rise between 0.9 and $3.5^{\circ} \mathrm{C}$ by the year 2100 . The classic pest and disease triangle recognizes the role of climate in plant, insect pest diseases as no virulent pathogen can induce disease in a highly susceptible host if climatic conditions are not favorable. Climate influences all stages of host and pathogen life cycles as well as development of disease. Pest and disease severity over a period can fluctuate according to climatic variation (Mina and Sinha, 2008).

Forewarning refers to the prediction of forthcoming infestation of the pest in numbers which would cause economic damage to the crop. It is of foremost importance in integrated pest management program as it serves as a tool to remain in preparing to face the exigencies. Weather based pest and disease forecast models are used in crop protection. For the purpose of development and use of these models, both meteorological and biological data are required as input, while the output is the anticipated outbreak of pest or disease. (Lingappa et al 2003).

Climate change has the potential to modify host physiology and resistance and to alter the stages and rates of development of the pest and pathogen. The most likely impacts would be shifted in the geographical distribution of the host, pest and pathogen, change in the physiology of host-pest and pathogen interactions and change in crop losses. New pest and disease complexes may arise and some pest and diseases may cease to be economically important if warming causes a pole ward shift of agro climatic zones and host plant migrate into new regions. The pathogen would be following the migrating hosts and may infect vegetation of natural plant communities not previously exposed to the often more aggressive strains of agricultural crops. The mechanism of pest and pathogen dispersal, suitability of the environment for dispersal, survival between seasons, and any change in host-physiology and ecology in the new environment will largely determine how quickly pest and pathogens become established in a region. 
https://doi.org/10.31426/ijamsr.2018.1.10.1012

\section{International Journal of Advanced Multidisciplinary Scientific Research (IJAMSR) ISSN:2581-4281}

Change may occur in the type, amount, and relative importance of pest/pathogens and affect the spectrum of pest/disease affecting particular crop. Plants growing in marginal climates could experience chronic stress that would predispose them to insect and disease outbreaks (Mina and Sinha, 2008).

Table 1. Recorded instances of recent insect pest outbreaks in relation to the changing climate scenario in India

\begin{tabular}{|c|c|c|c|c|c|c|}
\hline $\begin{array}{l}\text { Insect } \\
\text { pest }\end{array}$ & $\begin{array}{l}\text { Orde } \\
\text { r/ } \\
\text { Famil } \\
\mathbf{y}\end{array}$ & $\begin{array}{l}\text { Hos } \\
\text { t } \\
\text { pla } \\
\text { nt/ } \\
\text { s }\end{array}$ & $\begin{array}{l}\text { Reg } \\
\text { ion/ } \\
\text { loca } \\
\text { tion }\end{array}$ & $\begin{array}{l}\text { Probabl } \\
\text { e } \\
\text { reason/s }\end{array}$ & $\begin{array}{l}\text { Imp } \\
\text { act } \\
\text { of } \\
\text { pest } \\
\text { out } \\
\text { bre } \\
\text { ak }\end{array}$ & $\begin{array}{l}\text { Refe } \\
\text { renc } \\
\text { e }\end{array}$ \\
\hline $\begin{array}{l}\text { Sugar } \\
\text { cane } \\
\text { wooll } \\
\text { y } \\
\text { aphid } \\
\text { Cerat } \\
\text { ovacu } \\
\text { na } \\
\text { lanige } \\
\text { ra } \\
\text { Zehnt } \\
\text { ner }\end{array}$ & $\begin{array}{l}\text { Hemi } \\
\text { ptera: } \\
\text { Aphid } \\
\text { idae }\end{array}$ & $\begin{array}{l}\text { Sug } \\
\text { arca } \\
\text { ne }\end{array}$ & $\begin{array}{l}\text { Sug } \\
\text { arca } \\
\text { ne } \\
\text { belt } \\
\text { of } \\
\text { Kar } \\
\text { nata } \\
\text { ka } \\
\text { and } \\
\text { Mah } \\
\text { aras } \\
\text { htra } \\
\text { Stat } \\
\text { es } \\
\text { duri } \\
\text { ng } \\
200 \\
2-03\end{array}$ & $\begin{array}{l}* \text { Recent } \\
\text { abnormal } \\
\text { weather } \\
\text { patterns } \\
* \\
\text { Insecticid } \\
\text { e misuse }\end{array}$ & \begin{tabular}{|l}
$*$ \\
$30 \%$ \\
yiel \\
d \\
loss \\
es \\
$*$ \\
Redu \\
ced \\
cane \\
recov \\
ery
\end{tabular} & $\begin{array}{l}\text { Josh } \\
\text { i, } \\
\text { and } \\
\text { Vira } \\
\text { ktam } \\
\text { ath, } \\
2004 \\
; \\
\text { Srik } \\
\text { anth, } \\
2007\end{array}$ \\
\hline $\begin{array}{l}\text { Rice } \\
\text { plant } \\
\text { hoppers } \\
\text { ilparva } \\
\text { ta } \\
\text { lugens } \\
\text { (Stal) } \\
\text { and } \\
\text { Sogatel } \\
\text { la } \\
\text { furcifer } \\
a(\text { Horv } \\
\text { ath) }\end{array}$ & $\begin{array}{l}\text { Hemi } \\
\text { ptera: } \\
\text { Fulgo } \\
\text { ridae }\end{array}$ & $\begin{array}{l}\text { Ric } \\
\text { e }\end{array}$ & $\begin{array}{l}\text { Nort } \\
h \\
\text { Indi } \\
\mathrm{a}\end{array}$ & - do- & $\begin{array}{l}* \\
\text { Crop } \\
\text { failur } \\
\text { e } \\
\text { over } \\
\text { more } \\
\text { than } \\
33,00 \\
0 \text { ha } \\
\text { padd } \\
\text { y area }\end{array}$ & $\begin{array}{l}\text { IAR } \\
\text { I } \\
\text { New } \\
\text { s, } \\
2008 \\
\text { IRRI } \\
\text { New } \\
\text { s, } \\
2009\end{array}$ \\
\hline
\end{tabular}

\begin{tabular}{|c|c|c|c|c|c|c|}
\hline $\begin{array}{l}\text { Mealy } \\
\text { bug, } \\
\text { Phena } \\
\text { coccu } \\
\text { s } \\
\text { soleno } \\
\text { psis } \\
\text { Tinsle } \\
\text { y }\end{array}$ & $\begin{array}{l}\text { Hemi } \\
\text { ptera: } \\
\text { Pseud } \\
\text { ococc } \\
\text { idae }\end{array}$ & $\begin{array}{l}\text { Cott } \\
\text { on, } \\
\text { Vege } \\
\text { table } \\
\text { s and } \\
\text { orna } \\
\text { ment } \\
\text { als }\end{array}$ & $\begin{array}{l}\text { Cott } \\
\text { on } \\
\text { gro } \\
\text { win } \\
\mathrm{g} \\
\text { belt } \\
\text { of } \\
\text { the } \\
\text { cou } \\
\text { ntry }\end{array}$ & $\begin{array}{l}* \text { Recent } \\
\text { abnorma } \\
1 \text { weather } \\
\text { patterns } \\
* \\
\text { Insectici } \\
\text { de } \\
\text { misuse } \\
* \text { Changed } \\
\text { cropping } \\
\text { environm } \\
\text { ent(introd } \\
\text { uction of } \\
\text { Bt cotton) }\end{array}$ & $\begin{array}{l}* \\
\text { Hea } \\
\text { vy } \\
\text { yiel } \\
\text { d } \\
(30- \\
40 \\
\%) \\
\text { loss } \\
\text { to } \\
\text { the } \\
\text { cott } \\
\text { on } \\
* \text { Inc } \\
\text { reas } \\
\text { ed } \\
\text { cost } \\
\text { of } \\
\text { crop } \\
\text { prot } \\
\text { ecti } \\
\text { on } \\
\text { due } \\
\text { to } \\
\text { over } \\
\text { use } \\
\text { of } \\
\text { pest } \\
\text { icid } \\
\text { es }\end{array}$ & $\begin{array}{l}\text { Dha } \\
\text { wan } \\
\text { et } \\
\text { al., } \\
2007\end{array}$ \\
\hline $\begin{array}{l}\text { Papay } \\
\text { a } \\
\text { mealy } \\
\text { bug } \\
\text { Parac } \\
\text { occus } \\
\text { margi } \\
\text { natus }\end{array}$ & $\begin{array}{l}\text { Hemi } \\
\text { ptera: } \\
\text { Pseud } \\
\text { ococc } \\
\text { idae }\end{array}$ & $\begin{array}{l}\text { Pap } \\
\text { aya }\end{array}$ & $\begin{array}{l}\text { Tam } \\
\text { il } \\
\text { Nad } \\
\text { u, } \\
\text { Kar } \\
\text { nata } \\
\text { ka, } \\
\text { Mah } \\
\text { aras } \\
\text { htra }\end{array}$ & $\begin{array}{l}* \text { Recent } \\
\text { abnormal } \\
\text { weather } \\
\text { patterns } \\
\text { *Insectici } \\
\text { de misuse }\end{array}$ & $\begin{array}{l}\text { *Sig } \\
\text { nific } \\
\text { ant } \\
\text { yiel } \\
\text { d } \\
\text { loss } \\
\text { to } \\
\text { the } \\
\text { pap } \\
\text { aya } \\
\text { gro } \\
\text { wer } \\
\text { s }\end{array}$ & $\begin{array}{l}\text { Tan } \\
\text { war } \\
\text { et } \\
\text { al., } \\
2010\end{array}$ \\
\hline
\end{tabular}

Sources: International Journal of Scientific and Research Publications, Volume 2, Issue 11, November 20128 ISSN 2250-3153 
https://doi.org/10.31426/ijamsr.2018.1.10.1012

\section{International Journal of Advanced Multidisciplinary Scientific Research (IJAMSR) ISSN:2581-4281}

Table 2. Published reports of empirical studies on impact of climate change on future geographic range and distribution of insect pests.

\begin{tabular}{|c|c|c|c|c|}
\hline $\begin{array}{l}\text { Insec } \\
\text { t pest }\end{array}$ & $\begin{array}{l}\text { Or } \\
\text { der/ } \\
\text { Fa } \\
\text { mil } \\
\text { y }\end{array}$ & $\begin{array}{l}\text { Ho } \\
\text { st } \\
\text { pla } \\
\text { nt/ } \\
\text { S }\end{array}$ & $\begin{array}{l}\text { Impact on } \\
\text { insects/ } \\
\text { behavioural } \\
\text { response }\end{array}$ & Reference \\
\hline $\begin{array}{l}\text { Corn } \\
\text { earw } \\
\text { orms } \\
\text { Helio } \\
\text { this } \\
\text { zea } \\
\text { (Bod } \\
\text { die) } \\
\text { and } \\
\text { Helic } \\
\text { overp } \\
\text { a } \\
\text { armig } \\
\text { era } \\
\text { (Hub } \\
\text { ner) }\end{array}$ & $\begin{array}{l}\text { Lep } \\
\text { idopt } \\
\text { era: } \\
\text { Noct } \\
\text { uidae }\end{array}$ & $\begin{array}{l}\mathrm{Ma} \\
\text { ize }\end{array}$ & $\begin{array}{l}\text { Altitudes wise } \\
\text { range expansion } \\
\text { and increased } \\
\text { overwintering } \\
\text { survival in USA }\end{array}$ & $\begin{array}{l}\text { Diffenbaugh } \\
\text { et al., } 2008\end{array}$ \\
\hline $\begin{array}{l}\text { Euro } \\
\text { pean } \\
\text { corn } \\
\text { borer } \\
\text { Ostri } \\
\text { nia } \\
\text { nubil } \\
\text { alis }\end{array}$ & & $\begin{array}{l}\mathrm{Ma} \\
\text { ize }\end{array}$ & $\begin{array}{l}\text { * Northward } \\
\text { shifts in the } \\
\text { potential } \\
\text { distribution up to } \\
1220 \mathrm{~km} \text { are } \\
\text { estimated to } \\
\text { occur } \\
\text { * An additional } \\
\text { generation per } \\
\text { season }\end{array}$ & $\begin{array}{l}\text { Porter et al, } \\
1991\end{array}$ \\
\hline $\begin{array}{l}104 \\
\text { com } \\
\text { mon } \\
\text { micro } \\
\text { lepid } \\
\text { opter } \\
\text { a } \\
\text { speci } \\
\text { es } \\
\text { inhab } \\
\text { itant } \\
\text { in } \\
\text { Nethe } \\
\text { rland } \\
\text { s }\end{array}$ & $\begin{array}{l}\text { Lep } \\
\text { ido } \\
\text { pter } \\
\text { a }\end{array}$ & $\begin{array}{l}\text { Ma } \\
\text { ny } \\
\text { crop } \\
\text { s of } \\
\text { agric } \\
\text { ultur } \\
\text { al } \\
\text { imp } \\
\text { orta } \\
\text { nce }\end{array}$ & $\begin{array}{l}\text { Changing } \\
\text { patterns in } \\
\text { phenology and } \\
\text { distribution of } \\
\text { microlepidoptera } \\
\text { in the } \\
\text { Netherlands } \\
\text { *Advancement of } \\
\text { flight peak dates } \\
\text { almost by } 12 \text { days } \\
\text { since } 1975-1194 \\
\text { Changes in the } \\
\text { species } \\
\text { composition of } \\
\text { the local fauna }\end{array}$ & $\begin{array}{l}\text { Kuchlein and } \\
\text { Ellis, } 1997\end{array}$ \\
\hline $\begin{array}{l}\text { Old } \\
\text { world }\end{array}$ & & & $\begin{array}{l}\text { Phenomenal } \\
\text { increase in the }\end{array}$ & Cannon, 1998 \\
\hline
\end{tabular}

\begin{tabular}{|c|c|c|c|c|}
\hline $\begin{array}{l}\text { Boll } \\
\text { worm } \\
\text { Helic } \\
\text { overp } \\
\text { a } \\
\text { armig } \\
\text { era } \\
\text { (Hub } \\
\text { ner) }\end{array}$ & & & $\begin{array}{l}\text { United Kingdom } \\
\text { from 1969-2004 } \\
\text { and outbreaks at } \\
\text { the northern edge } \\
\text { of its range in } \\
\text { Europe }\end{array}$ & \\
\hline $\begin{array}{l}\text { Cotto } \\
\text { ny } \\
\text { cushi } \\
\text { on } \\
\text { scale } \\
\text { Icery } \\
\text { a } \\
\text { purch } \\
\text { asi }\end{array}$ & & & $\begin{array}{l}* \text { Populations } \\
\text { appear to be } \\
\text { spreading } \\
\text { northwards }\end{array}$ & Cannon, 1998 \\
\hline $\begin{array}{l}\text { Oak } \\
\text { proce } \\
\text { ssion } \\
\text { ary } \\
\text { moth } \\
\text { Thau } \\
\text { meto } \\
\text { poea } \\
\text { proce } \\
\text { ssion } \\
\text { ea }\end{array}$ & & & $\begin{array}{l}\text { *Northward range } \\
\text { extension from cen } \\
\text { southern Europe in } \\
\text { Belgium, Netherlan } \\
\text { Denmark }\end{array}$ & $\begin{array}{l}\text { tral and } \\
\text { to } \\
\text { Cannon, } 1998\end{array}$ \\
\hline $\begin{array}{l}\text { Cotto } \\
\text { ny } \\
\text { camel } \\
\text { lia } \\
\text { scale } \\
\text { Chlor } \\
\text { opulv } \\
\text { inari } \\
\text { a } \\
\text { flocci } \\
\text { fera }\end{array}$ & & & $\begin{array}{l}\text { *More abundant } \\
\text { in the United } \\
\text { Kingdom, } \\
* \text { Extending its } \\
\text { range northwards } \\
\text { in England and } \\
\text { increasing its } \\
\text { host range in the } \\
\text { last decade }\end{array}$ & Cannon, 1998 \\
\hline $\begin{array}{l}35 \\
\text { speci } \\
\text { es of } \\
\text { non } \\
\text { migra } \\
\text { tory } \\
\text { Euro } \\
\text { pean } \\
\text { butter } \\
\text { flies }\end{array}$ & \begin{tabular}{|l} 
Papil \\
ionid \\
ae, \\
Lyca \\
enida \\
e, \\
Nym \\
phali \\
dae, \\
Satyr \\
inae
\end{tabular} & & $\begin{array}{l}* \text { Pole ward shift } \\
\text { of the geographic } \\
\text { range and } \\
\text { distribution }\end{array}$ & $\begin{array}{l}\text { Parmesan and } \\
\text { Yohe, } 2003\end{array}$ \\
\hline $\begin{array}{l}\text { Cotto } \\
\mathrm{n}\end{array}$ & $\begin{array}{l}\text { Lep } \\
\text { ido }\end{array}$ & $\begin{array}{l}\text { Cot } \\
\text { ton }\end{array}$ & $\begin{array}{l}* \text { Expansion of } \\
\text { geographic range }\end{array}$ & $\begin{array}{l}\text { Sharma et al., } \\
\text { 2005; } 2010\end{array}$ \\
\hline
\end{tabular}


https://doi.org/10.31426/ijamsr.2018.1.10.1012

\section{International Journal of Advanced Multidisciplinary Scientific Research (IJAMSR) ISSN:2581-4281}

\begin{tabular}{|l|l|l|l|l|}
\hline bollw & pter &, & in Northern India & \\
orm/ & a: & Pul & *Adult flights/ & \\
Pulse & Noc & ses & $\begin{array}{l}\text { migratory } \\
\text { behavior }\end{array}$ & \\
pod & tuid &, & ae & \\
borer & ae & veg & & \\
Helic & & eta & & \\
overp & & ble & & \\
a & & s & & \\
armig & & & & \\
era & & & & \\
(Hub & & & & \\
ner) & & & & \\
\hline
\end{tabular}

Effect of Elevated Carbon Dioxide on Crop, Pest Dynamics

A larger crop canopy and denser foliage resulted from enhanced $\mathrm{CO}_{2}$ level in the atmosphere will create more relative humidity, thereby making the micro environment more favorable for pests. Increases in food quality, i.e. increase in the nitrogen content of plants due to high temperature, can result in a sudden resurgence of population of pests. Moreover, under condition of stress, plant defensive systems are less effective and they become more susceptible to pest attack (Coviella and Trumble 1999). Some more findings on the effects of enhanced $\mathrm{CO}_{2}$ on crop pests are given in the table 1 .

Table 1. Effect of increasing atmospheric carbon dioxide on plant, insect interaction.

\begin{tabular}{|c|c|}
\hline $\begin{array}{l}\text { Increasing atmospheric } \\
\text { carbon dioxide leads to }\end{array}$ & References \\
\hline $\begin{array}{l}\text { Increasing... } \\
\text { Food consumption by } \\
\text { caterpillars } \\
\text { Reproduction of aphids } \\
\text { Predation by lady beetle } \\
\text { Carbon based plant } \\
\text { defenses } \\
\text { Effect of foliar application } \\
\text { and B.thuringiensis }\end{array}$ & $\begin{array}{l}\text { Osbrink et al., } 1987 \\
\text { Bezemer } \text { et al., } 1999 \\
\text { Chen } \text { et al., } 2005 \\
\text { Coviella and Trumble, } \\
1999 \\
\text { Coviella and Trumble, } \\
2000\end{array}$ \\
\hline $\begin{array}{l}\text { Decreasing... } \\
\text { Insect development rates } \\
\text { Response to alarm } \\
\text { pheromones by aphids } \\
\text { Parasitism } \\
\text { Effect of transgenic } B . \\
\text { thuringiensis } \\
\text { Nitrogen-based plant } \\
\text { defense }\end{array}$ & $\begin{array}{l}\text { Osbrink et al., } 1987 \\
\text { Awmarck et al., } 2000 \\
\text { Roth and Lndroth, } 1995 \\
\text { Coviella } \text { et al., } 2000 \\
\text { Coviella and Trumble, } \\
1999\end{array}$ \\
\hline
\end{tabular}

\section{Impact of Enhanced Temperature on Crop, Pest Dynamics}

Insects are cold-blooded organisms - the temperature of their bodies is approximately the same as that of the environment. Therefore, temperature is probably the single most important environmental factor influencing insect behavior, distribution, development, survival, and reproduction. Some researchers believe that the effect of temperature on insects largely overwhelms the effects of other environmental factors (Bale et al., 2002). It has been estimated that with a $\mathrm{CO}_{2}$ temperature increase, insects might experience one to five additional life cycles per season (Yamamura and Kiritani 1998). Other researchers have found that moisture and $\mathrm{CO}_{2}$ effects on insects can be potentially important considerations in a global climate change, setting (Coviella and Trumble 1999; Hunter 2001). For every insect species there is a range of temperature within 


\section{International Journal of Advanced Multidisciplinary Scientific Research (IJAMSR) ISSN:2581-4281}

which it remains active from egg to adult stage. Lower values of this range are called 'threshold of development' or 'developmental zero'. Within the favorable range, there is an optimum temperature at which most of the individuals of a species complete their development. Exposure to temperatures on either side of the range exerts an adverse impact on the insect by slowing down the speed of development. The possible impacts of increased atmospheric temperature on crop pests found by other researchers are summarized in table 2.

Table 2 Effect of enhanced atmospheric temperature on crop pest dynamics

\begin{tabular}{|c|c|}
\hline $\begin{array}{l}\text { Increasing atmospheric } \\
\text { temperature leads to }\end{array}$ & Reference \\
\hline $\begin{array}{l}\text { Increasing... } \\
\text { Northward migration } \\
\text { Migration up elevation } \\
\text { gradients } \\
\text { Insect developmental rates } \\
\text { and oviposition } \\
\text { Potential for insect } \\
\text { outbreaks } \\
\text { Invasive } \\
\text { introductions } \\
\text { Insect extinctions }\end{array}$ & $\begin{array}{l}\text { Parmesan, } 2006 \\
\text { Epstein } \text { et al., } 1998 \\
\text { Regniere, } 1983 \\
\text { Bale } \text { et al., } 2002 \\
\text { Dukes and Mooney, } 1999 \\
\text { Thomas } \text { et al., } 2004\end{array}$ \\
\hline $\begin{array}{l}\text { Decreasing... } \\
\text { Effectiveness of insect } \\
\text { biocontrol by fungi } \\
\text { Reliability of } \\
\text { economic threshold } \\
\text { levels } \\
\text { Insect diversity in } \\
\text { ecosystems } \\
\text { Parasitism } \\
1995\end{array}$ & $\begin{array}{l}\text { Stacy and Fellowes, } 2002 \\
\text { Trumble, John and Butler, } \\
\text { Casey, } 2009 \\
\text { Erasmus } \text { et al., } 2002 \\
\text { Hance et al., 2007; } \\
\text { Fleming and Volney, }\end{array}$ \\
\hline
\end{tabular}

Role of India Meteorological Department for forewarning of crop pest outbreak
Every year crops are being damaged by pests and diseases. Due to lack of proper operational forecasting system for the incidences of pests and diseases, it becomes difficult to adopt plant protection measures at right time. It has been established with a fair degree of accuracy that climate/weather plays major role in the incidences of pests and diseases. Thus, there is great scope of utilizing meteorological parameters for the advance information about the occurrences of pests and diseases and ultimately scheduling of prophylactic measures can be taken scientifically and judiciously. Quite a number of studies on the relation between meteorological parameters and pest and disease incidences have already been made in India.

(Chattopadhyay, $\mathrm{N}$ et.al, 2011) Weather based pests and disease models to dissemination of the advance information to the farmers through different state of the art information technology, are being taken to control and minimize the loss of crops due to pests and disease incidences.

Meteorological Department plays an important role for prediction of crop pest with the help of location specific research center historical data of crop pest and climate. On the basis of historical data on weather and crop pest find the congenial weather condition for an outbreak of crop pest on the specific location. The feasibility of meteorological forewarning of aphid, jassid, thips, mird and pink bollworm of cotton. A critical analysis of correlation coefficients between the light trap catches of gall midge and stem borer of rice and meteorological parameters showed that there are turning points and epicenters of outbreak of both the pests. The study also revealed that maximum and minimum temperature, morning and afternoon relative humidity, bright sunshine hours and weekly total rainfall have a profound 


\section{International Journal of Advanced Multidisciplinary Scientific Research (IJAMSR) ISSN:2581-4281}

effect on the development of gall midge and stem borer at their successive generations. Due to variation in weather parameters within the season and inter season between kharif and rabi the maximum peaks of gall midge and stem borer infestations were observed respectively in kharif and rabi seasons. Favorable weather conditions for the development of gall midge and stem borer at each of the generations were worked out and discussed.

Weather based forewarning models/guidelines for the peak infestation period for important pests of major crops were developed. Pest weather calendars for important pests were also prepared for operational crop protection. These pest, weather calendars, present and forecast weather and pest observations from the field would help the Agromet Advisory Units of IMD to issue forewarning of pest outbreak and also to advise the farming community to decide their spraying and dusting operations. An attempt has been made to use operational pests and diseases management scheme which not only reduce the damage lower than the economic injury level, but also support the growth and survival of its natural enemies. The need to minimize the use of noxious chemicals through proper application of the right chemicals at the right time using weather based information has been emphasized. The India Meteorological Department developed and validates several crop pest forewarning models are given by table. 3.
Table 3: Various crop pests their congenial weather condition and regression model for forewarning of crop pest

\begin{tabular}{|c|c|c|c|c|c|}
\hline $\begin{array}{l}\text { Crop/ } \\
\text { Pests }\end{array}$ & $\begin{array}{l}\text { Station } \\
/ \\
\text { Climat } \\
\text { ic zone }\end{array}$ & $\begin{array}{l}\text { Peri } \\
\text { od } \\
\text { of } \\
\text { dam } \\
\text { age }\end{array}$ & $\begin{array}{l}\text { Stage } \\
\text { of the } \\
\text { crop }\end{array}$ & $\begin{array}{l}\text { Cong } \\
\text { enial } \\
\text { weath } \\
\text { er } \\
\text { condi } \\
\text { tion }\end{array}$ & $\begin{array}{l}\text { Regressi } \\
\text { on } \\
\text { model }\end{array}$ \\
\hline $\begin{array}{c}\text { Cotto } \\
\text { n/ } \\
\text { Jassi } \\
\text { d }\end{array}$ & $\begin{array}{l}\text { Akola/ } \\
\text { Central } \\
\text { vidarbh } \\
\text { a }\end{array}$ & $\begin{array}{l}\text { End } \\
\text { of } \\
\text { July } \\
\text { to } \\
\text { mid- } \\
\text { of } \\
\text { Oct }\end{array}$ & $\begin{array}{l}\text { Elongat } \\
\text { ion } \\
\text { /flower } \\
\text { ing/init } \\
\text { ial boll } \\
\text { formati } \\
\text { on }\end{array}$ & $\begin{array}{l}\text { After } \\
\text { noon } \\
\text { RH<7 } \\
2, \text { SSH } \\
\leq 4.4 \\
\text { hrs } \\
\text { and } \\
\mathrm{T}_{\min } \geq \\
22.4\end{array}$ & $\begin{array}{l}\text { Ic }=-62.3 \\
+7.35, \text { Tmi } \\
\text { n( } 36^{\text {th }} \\
\text { S.W })-1.5 \\
\text { RH1 }\left(37^{\text {th }}\right. \\
\text { S.W })+0.62 \\
\text { RH2 }\left(37^{\text {th }}\right. \\
\text { SW) }\end{array}$ \\
\hline $\begin{array}{c}\text { Thrip } \\
\text { s }\end{array}$ & & $\begin{array}{l}\text { July } \\
\text { to } \\
\text { Nov }\end{array}$ & $\begin{array}{l}\text { Elongat } \\
\text { ion } \\
\text { /flower } \\
\text { ing/ } \\
\text { initial } \\
\text { boll } \\
\text { formati } \\
\text { on }\end{array}$ & \begin{tabular}{|l} 
Tmean \\
$>=$ \\
26.8 \\
${ }^{\circ} \mathrm{C}$, \\
Ssh > \\
$=6.4$ \\
hrs., \\
Rh2 \\
$<=$ \\
$67 \%$
\end{tabular} & $\begin{array}{l}\mathrm{I}_{\mathrm{C}}=- \\
827.3- \\
23.7 \mathrm{Rh} 2 \\
+8.1 \mathrm{Ssh} \\
+24.34 \\
(33 \mathrm{rd} \\
\text { week) }\end{array}$ \\
\hline$\underset{\text { d }}{\text { Aphi }}$ & & $\begin{array}{l}\text { July } \\
\text { to } \\
\text { Jan }\end{array}$ & $\begin{array}{l}\text { Elongat } \\
\text { ion to } \\
\text { boll } \\
\text { formati } \\
\text { on }\end{array}$ & 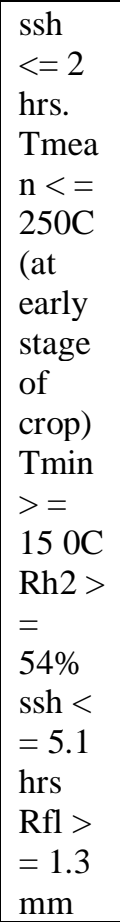 & $\begin{array}{l}\mathrm{I}_{\mathrm{C}}=0.18 \\
+0.44 \\
\text { Tmin- } 18 \\
\mathrm{Rh} 2+ \\
0.16 \mathrm{ssh} \\
+29.9 \\
\text { Rfl (45th } \\
\text { week) }\end{array}$ \\
\hline
\end{tabular}


https://doi.org/10.31426/ijamsr.2018.1.10.1012

\section{International Journal of Advanced Multidisciplinary Scientific Research (IJAMSR) ISSN:2581-4281}

\begin{tabular}{|c|c|c|c|c|c|}
\hline \multirow[t]{2}{*}{$\begin{array}{c}\text { Pink } \\
\text { Bollw } \\
\text { orm }\end{array}$} & \multirow[t]{2}{*}{$\begin{array}{l}\text { Parbh } \\
\text { ani } \\
\text { /Centra } \\
1 \\
\text { Vidarb } \\
\text { ha }\end{array}$} & $\begin{array}{l}\text { Oct } \\
\text { to } \\
\text { mid } \\
\text { Dec }\end{array}$ & $\begin{array}{l}\text { Floweri } \\
\text { ng } \\
\text { to boll } \\
\text { formati } \\
\text { on }\end{array}$ & $\begin{array}{l}\mathrm{T}_{\min }> \\
20{ }^{0} \mathrm{C} \\
\mathrm{Rh}_{1}> \\
60 \% \\
\mathrm{Rfl}> \\
0.5 \\
\mathrm{~mm}, \\
\text { Cloud } \\
\text { ing }\end{array}$ & $\begin{array}{l}\mathrm{I}_{\mathrm{C}}=- \\
27.5+ \\
0.83 \\
\text { Tmin }+ \\
1.7 \mathrm{Ssh}+ \\
32.3 \mathrm{Rfl} \\
\left(42^{\text {nd }} \text { wee }\right. \\
\mathrm{k})\end{array}$ \\
\hline & & $\begin{array}{l}\text { Oct } \\
\text { to } \\
\text { mid } \\
\text { Dec }\end{array}$ & $\begin{array}{l}\text { Floweri } \\
\text { ng } \\
\text { to boll } \\
\text { formati } \\
\text { on }\end{array}$ & $\begin{array}{l}\mathrm{Rh}_{1}> \\
60 \%, \\
\text { Tmea } \\
\mathrm{n}: \\
24- \\
28^{0} \mathrm{C}, \\
\mathrm{Rfl}> \\
0.5 \\
\text { mm } \\
\text { Cloud } \\
\text { ing }\end{array}$ & $\begin{array}{l}\mathrm{I}_{\mathrm{C}}=8.8- \\
0.18 \\
\mathrm{Rh}{ }_{2}+0.3 \\
\mathrm{Rfl} \\
\left(42^{\text {nd }} \text { wee }\right. \\
\mathrm{k})\end{array}$ \\
\hline \multirow[t]{4}{*}{$\begin{array}{l}\text { Amer } \\
\text { ican } \\
\text { Bollw } \\
\text { orm }\end{array}$} & $\begin{array}{l}\text { Akola/ } \\
\text { Central } \\
\text { Vidarb } \\
\text { ha }\end{array}$ & $\begin{array}{c}\text { Aug } \\
\text { ust } \\
\text { to } \\
\text { Dec }\end{array}$ & $\begin{array}{l}\text { Elongat } \\
\text { ion to } \\
\text { boll } \\
\text { develo } \\
\text { pment }\end{array}$ & $\begin{array}{l}\mathrm{T}_{\min }< \\
11^{0} \mathrm{C} \\
\mathrm{Rh}_{2}< \\
18 \%\end{array}$ & ---- \\
\hline & $\begin{array}{l}\text { Coimb } \\
\text { atore/- }\end{array}$ & $\begin{array}{l}\text { Sept } \\
\text { to } \\
\text { Nov }\end{array}$ & $\begin{array}{c}\text { Floweri } \\
\text { ng to } \\
\text { picking }\end{array}$ & $\begin{array}{l}\mathrm{T}_{\text {mean }}< \\
30^{0} \mathrm{C} \\
\mathrm{Rh}_{2}< \\
\text { below } \\
\text { norma } \\
1\end{array}$ & ---- \\
\hline & $\begin{array}{l}\text { Nagpu } \\
\text { r, } \\
\text { Wardh } \\
\text { a,/ } \\
\text { Eastern } \\
\text { Vidarb } \\
\text { ha }\end{array}$ & $\begin{array}{l}\text { Sept } \\
\text { to } \\
\text { Nov }\end{array}$ & $\begin{array}{l}\text { Floweri } \\
\text { ng to } \\
\text { boll } \\
\text { formati } \\
\text { on }\end{array}$ & $\begin{array}{l}\text { Prolo } \\
\text { ng dry } \\
\text { condit } \\
\text { ion } \\
\mathrm{T}_{\min }< \\
23{ }^{\circ} \mathrm{C} \\
\mathrm{Rh}_{1}< \\
80 \% \\
\mathrm{Rh}_{2}< \\
60 \%\end{array}$ & ---- \\
\hline & $\begin{array}{l}\text { Gangan } \\
\text { agar,/ } \\
\text { Irrigated } \\
\text { North } \\
\text { Wester } \\
\text { n plain }\end{array}$ & $\begin{array}{l}\text { Sept } \\
\text { to } \\
\text { Nov }\end{array}$ & $\begin{array}{l}\text { Floweri } \\
\quad \text { ng to } \\
\text { Boll } \\
\text { formatio } \\
\text { n }\end{array}$ & $\begin{array}{l}\text { Prolo } \\
\text { ng dry } \\
\text { condit } \\
\text { ion } \\
\text { Tmin } \\
<23^{\circ} \mathrm{C} \\
\mathrm{Rh}_{1}< \\
80 \% \\
\mathrm{Rh}_{2}< \\
60 \% \\
\end{array}$ & ---- \\
\hline $\begin{array}{l}\text { Spott } \\
\text { ed } \\
\text { Bollw } \\
\end{array}$ & $\begin{array}{l}\text { Surat } \\
\text { (Gujar } \\
\text { at) } /--\end{array}$ & $\begin{array}{l}\text { Oct } \\
\text { to } \\
\text { Dec }\end{array}$ & $\begin{array}{l}\text { Boll } \\
\text { formati } \\
\text { on }\end{array}$ & $\begin{array}{l}\text { Ssh : } \\
5-7 \\
\text { hrs. }\end{array}$ & --- \\
\hline
\end{tabular}

\begin{tabular}{|c|c|c|c|c|c|}
\hline orm & & & & $\begin{array}{l}\text { Rh1 : } \\
95 \\
100 \% \\
\text { Rfl } \\
\text { (week } \\
\text { ly } \\
\text { total) } \\
: \quad 170 \\
-\quad 210 \\
\text { mm } \\
\text { (Last } \\
\text { week } \\
\text { ofAug } \\
\text { ust) }\end{array}$ & \\
\hline $\begin{array}{c}\text { Grou } \\
\text { ndnut } \\
\text { /Leaf } \\
\text { Mino } \\
\text { r }\end{array}$ & $\begin{array}{c}\text { Akola/ } \\
\text { Central } \\
\text { Vidarb } \\
\text { ha }\end{array}$ & $\begin{array}{l}\text { Aug } \\
\text { ust } \\
\text { Sept } \\
\text { emb } \\
\text { er }\end{array}$ & $\begin{array}{l}\text { Pod } \\
\text { formatio } \\
\text { n to Pod } \\
\text { ripening }\end{array}$ & $\begin{array}{l}\text { Tmax } \\
<31 \\
{ }^{\circ} \mathrm{C} \\
\mathrm{Rh} 1: \\
85 \% \\
\mathrm{Ssh}> \\
3 \mathrm{hrs} . \\
\text { Occas } \\
\text { ional } \\
\text { rain }\end{array}$ & \\
\hline $\begin{array}{c}\text { Pigeo } \\
\text { n } \\
\text { pea/H } \\
\text { elioth } \\
\text { is } \\
\text { Armi } \\
\text { gera }\end{array}$ & $\begin{array}{l}\text { Rahuri } \\
\text { / } \\
\text { Central } \\
\text { Mahara } \\
\text { shtra } \\
\text { Plateau }\end{array}$ & $\begin{array}{l}\text { (Jun } \\
\text { e to } \\
\text { Nov } \\
\text { ) \& } \\
\text { (No } \\
\text { v to } \\
\text { Mar } \\
\text { ch) }\end{array}$ & $\begin{array}{l}\text { Floweri } \\
\text { ng to } \\
\text { Pod } \\
\text { formati } \\
\text { on }\end{array}$ & $\begin{array}{l}\text { Tmin } \\
< \\
12^{\circ} \mathrm{C} \\
, \text { Rh1 } \\
<80 \\
\% \\
\text { Rh2< } \\
45 \% \\
, \text { Ssh } \\
>6.6 \\
\text { hours }\end{array}$ & ---- \\
\hline $\begin{array}{l}\text { Toma } \\
\text { to/ } \\
\text { Early } \\
\text { blight }\end{array}$ & $\begin{array}{l}\text { Pune } \\
\text { Central } \\
\text { Mahara } \\
\text { shtra } \\
\text { Plateau }\end{array}$ & $\begin{array}{l}\text { Sept } \\
\text { to } \\
\text { Nov }\end{array}$ & ----- & $\begin{array}{l}\text { Tmax } \\
: 3^{\circ} \mathrm{C} \\
\text { above } \\
\text { norma } \\
1\end{array}$ & ---- \\
\hline $\begin{array}{l}\text { Potat } \\
\text { o } \\
\text { /Potat } \\
\text { o } \\
\text { Beetl } \\
\text { e } \\
\end{array}$ & & $\begin{array}{l}\text { Any } \\
\text { time } \\
\text { when } \\
\text { cultiv } \\
\text { ated }\end{array}$ & ---- & $\begin{array}{l}\text { Statio } \\
\mathrm{n} \\
\text { annua } \\
1 \\
\text { rainfa } \\
\text { ll : }\end{array}$ & \\
\hline
\end{tabular}


https://doi.org/10.31426/ijamsr.2018.1.10.1012

\begin{tabular}{|c|c|c|c|c|c|}
\hline & & & & $\begin{array}{l}600- \\
1500 \\
\text { mm } \\
\text { Temp. } \\
\text { range } \\
:-4 \text { to } \\
+ \\
38^{\circ} \mathrm{C} \\
\text { Favor } \\
\text { able } \\
\text { soil } \\
\text { temp. }\end{array}$ & \\
\hline $\begin{array}{c}\text { Rice } \\
\text { /Gall } \\
\text { Midg } \\
\text { e }\end{array}$ & $\begin{array}{l}\text { Patta } \\
\text { mbi }\end{array}$ & July & $\begin{array}{l}\text { Vegetat } \\
\text { ive }\end{array}$ & $\begin{array}{l}T_{\max }> \\
28.9^{\circ} \\
\mathrm{C} \\
\text { Ssh > } \\
2.5 \\
\text { hrs }\end{array}$ & $\begin{array}{l}\mathrm{I}_{\mathrm{C}}=- \\
521.9+18 . \\
63 \\
\mathrm{~T}_{\max }(30 \text { th } \\
\mathrm{S} . \mathrm{W})- \\
2.73 \\
\mathrm{Ssh}(30 \text { th } \\
\mathrm{S} . \mathrm{W}) \\
{[\text { for } 1 \text { st }} \\
\text { generatio } \\
\mathrm{n} \\
\text { of pest at } \\
\text { 32nd } \\
\text { S.W(6- } \\
\text { 12August } \\
\text { )] }\end{array}$ \\
\hline \multirow[t]{2}{*}{$\begin{array}{c}\text { Gree } \\
\text { n } \\
\text { Jassi } \\
\text { d }\end{array}$} & \multirow[t]{2}{*}{$\begin{array}{l}\text { Patta } \\
\text { mbi }\end{array}$} & July & $\begin{array}{l}\text { Vegetat } \\
\text { ive }\end{array}$ & $\begin{array}{l}\mathrm{T}_{\min }< \\
22.1^{\circ} \\
\mathrm{C}\end{array}$ & $\begin{array}{l}\mathrm{IC}=3853 . \\
6-76.3 \\
\mathrm{~T}_{\max } \\
120.4 \\
\mathrm{~T}_{\min }\left(30^{\text {th }}\right. \\
\mathrm{S} . \mathrm{W})+16 . \\
9 \mathrm{Rh}_{2}-8.8 \\
\mathrm{Ssh}+0.5 \mathrm{R} \\
\mathrm{fl}[\text { for } \\
1^{\text {st }} \text { genera } \\
\text { tion of } \\
\text { pest at } \\
33^{\text {rd }} \mathrm{S} . \mathrm{W}( \\
13-19 \\
\text { August] }\end{array}$ \\
\hline & & $\begin{array}{l}\text { Aug } \\
\text { ust }\end{array}$ & $\begin{array}{c}\text { Floweri } \\
\text { ng }\end{array}$ & $\begin{array}{l}\mathrm{T}_{\max }< \\
29.5 \\
{ }^{\circ} \mathrm{C} \\
\mathrm{Rh}_{2}> \\
75.2 \\
\% \text { Ssh } \\
<4 \\
\text { hrs. } \\
\text { Rf }>\end{array}$ & $\begin{array}{l}\mathrm{IC}=1461 . \\
6-105.0 \\
\text { Tmax- } \\
124.4 \mathrm{Rh}_{1}- \\
1.96 \\
\mathrm{Rh}_{2}+131 . \\
8 \mathrm{Ssh} \text { ) } \\
{[\text { for }} \\
2^{\text {nd }} \text { genera } \\
\end{array}$ \\
\hline
\end{tabular}

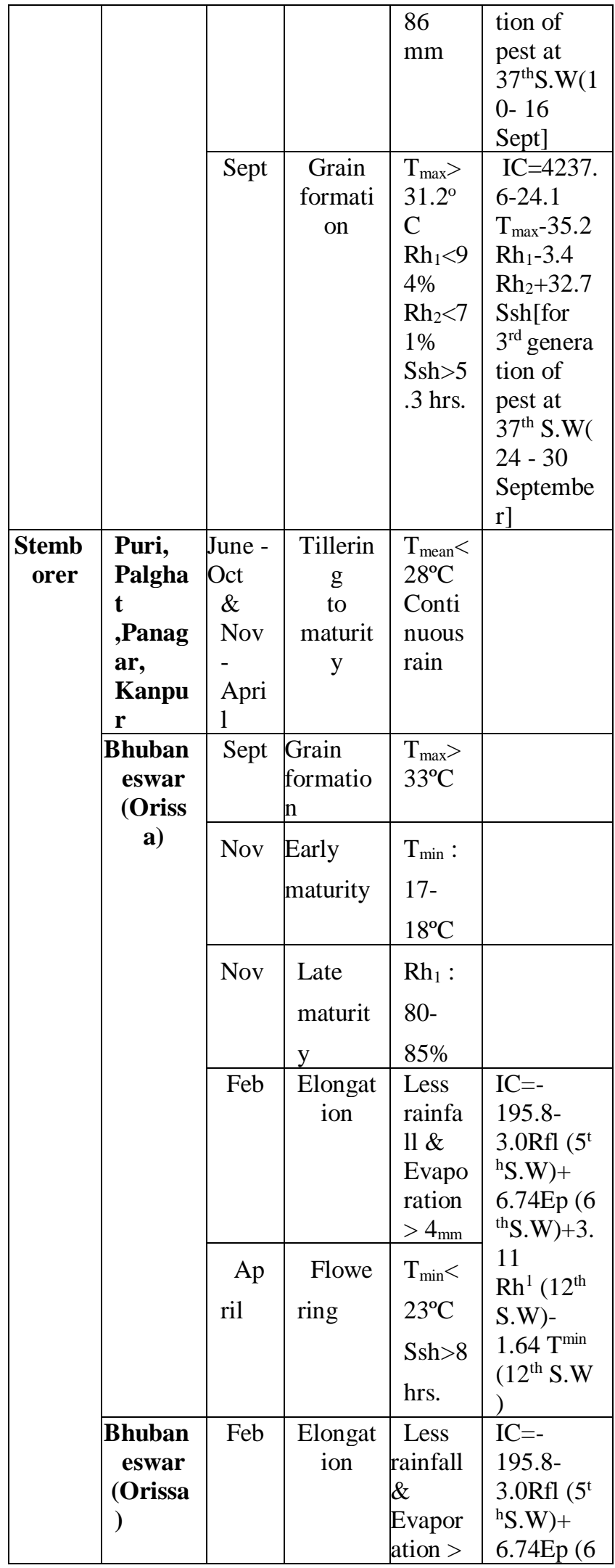


https://doi.org/10.31426/ijamsr.2018.1.10.1012

I J A M S R

International Journal of

Advanced Multidisciplinary Scientific Research (IJAMSR) ISSN:2581-4281

\begin{tabular}{|c|c|c|c|c|}
\hline & & & $4_{\mathrm{mm}}$ & \multirow{2}{*}{$\begin{array}{l}\left.{ }^{\text {th }} . \mathrm{W}\right)+3 . \\
11 \\
\mathrm{Rh}^{1}\left(12^{\text {th }}\right. \\
\text { S.W })- \\
1.64 \mathrm{~T}^{\text {min }} \\
\left(12^{\text {th }} \mathrm{S} . \mathrm{W}\right. \\
)\end{array}$} \\
\hline & $\begin{array}{l}\text { Ap } \\
\text { ril }\end{array}$ & $\begin{array}{l}\text { Flowe } \\
\text { ring }\end{array}$ & $\begin{array}{l}\mathrm{T}_{\min }< \\
23^{\circ} \mathrm{C} \\
\mathrm{Ssh}>8 \\
\text { hrs. }\end{array}$ & \\
\hline \multirow[t]{4}{*}{$\begin{array}{l}\text { Patta } \\
\text { mbi }\end{array}$} & $\begin{array}{c}\text { Dec } \\
\text { (pre } \\
\text { viou } \\
\text { s } \\
\text { year } \\
\text { ) } \\
\end{array}$ & $\begin{array}{c}\text { Non- } \\
\text { crop } \\
\text { season }\end{array}$ & \begin{tabular}{|l} 
Soil \\
Temper \\
ature < \\
$24^{\circ} \mathrm{C}$
\end{tabular} & \multirow{4}{*}{$\begin{array}{l}\mathrm{IC}=395.3 \\
1- \\
4.80 \mathrm{St}(51 \\
\text { st.W)- } \\
6.50 \mathrm{Tmax} \\
\left(14^{\text {th }} \mathrm{S} . \mathrm{W}\right. \\
) \\
\mathrm{IC}=- \\
61.0+ \\
3.834 \mathrm{Ssh} \\
\left(30^{\text {th }} \mathrm{S} . \mathrm{W}\right. \\
) \\
+5.8 \mathrm{~T}_{\max } \\
\left(31^{\text {st }} \mathrm{S} . \mathrm{W}\right) \\
- \\
1.0 \mathrm{Rh} \\
\left(36^{\text {th }} \mathrm{S} . \mathrm{W}\right. \\
)\end{array}$} \\
\hline & $\begin{array}{l}\text { Apr } \\
\text { il }\end{array}$ & $\begin{array}{l}\text { Non- } \\
\text { crop } \\
\text { season }\end{array}$ & $\begin{array}{l}\mathrm{T}_{\max }< \\
36^{\circ} \mathrm{C}\end{array}$ & \\
\hline & July & $\begin{array}{l}\text { Vegeta } \\
\text { tive }\end{array}$ & $\begin{array}{l}\mathrm{Ssh}> \\
4 \mathrm{hrs} . \\
\mathrm{T}_{\max }> \\
28.8 \\
{ }^{\circ} \mathrm{C} \\
\end{array}$ & \\
\hline & Sept & $\begin{array}{l}\text { Grain } \\
\text { formati } \\
\text { on }\end{array}$ & $\begin{array}{l}\mathrm{Rh} 2< \\
71 \%\end{array}$ & \\
\hline \multirow[t]{2}{*}{$\begin{array}{l}\text { Patta } \\
\text { mbi }\end{array}$} & Nov & Sowing & $\begin{array}{l}\mathrm{T}_{\max }< \\
31.9 \\
{ }^{\circ} \mathrm{C}, \\
\mathrm{Rh} 1< \\
94 \%, \\
\mathrm{Rfl}< \\
28.2 \\
\mathrm{~mm}\end{array}$ & \\
\hline & Dec & $\begin{array}{l}\text { Transpl } \\
\text { anting }\end{array}$ & $\begin{array}{l}\text { Tmax } \\
<32.8 \\
{ }^{\circ} \mathrm{C}, \\
\mathrm{Rh} 1< \\
81 \%, \\
\mathrm{Rh} 2< \\
47 \%\end{array}$ & \\
\hline
\end{tabular}

\section{Source: India Meteorological Department (IMD)}

Role of National Centre for Integrated Pest Management (NCIPM) for forewarning of crop pest outbreak under the impact of climate change scenario
National Centre for Integrated Pest Management plays an important role for forewarning of insect pest under the impact of climate change under the project entitled national initiative climate resilient agriculture (NICRA) and CROPSAP project. There are several prediction rules developed and validate for crop pest (NCIPM, news letter January to June 2012, Research Highlight.

Prediction of cotton sap feeders at Central India

Jassids: Weather based criteria viz., mean temperature of $25-28^{\circ} \mathrm{C}$, mean humidity of $65-85 \%$, total rainfall of $50-$ $80 \mathrm{~mm}$ and rainy days between 2 and 4 days of any standard meteorological week predict the severity levels based on mean jassid population per three leaves were categorized as too high $(>8)$, moderate $(>4-8)$ and low $(<4)$. All four, three and two or less of the formulated, weather criteria being satisfied predict high, moderate and low levels of jassid severity, respectively.

Mirids: Fulfilling e"5, four and d"3 of the six weather based criteria viz., maximum temperature

$>310 \mathrm{C}$, minimum temperature between $21 \& 24^{\circ} \mathrm{C}$, relative humidity (morning) $>85 \%$, relative humidity evening between $30-70 \%$, rainfall $<25 \mathrm{~mm}$ and rainy days between 2 and 4 days on weekly basis predict the severity of mirids (Campylomma livida Reuter) on $\mathrm{Bt}$ cotton as to high (>4 nos/plant), moderate (>2-4 nos/ plant) and low (0-2 nos/ plant), respectively. 


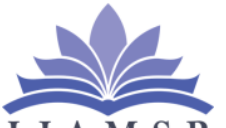

I J A M S R

\section{International Journal of} Advanced Multidisciplinary Scientific Research (IJAMSR) ISSN:2581-4281

Thrips: Mean temperature of $25-29^{\circ} \mathrm{C}$, mean humidity of $67-86 \%$, total rainfall of $30-80 \mathrm{~mm}$

and rainy days between 3 and 6 days of any standard meteorological week predict the levels of severity of thrips in conjunction with severity levels categorized based on mean thrips population per three leaves as to high $(>10)$, moderate $(>5-10)$ and low $(<5)$. All four, three and two or less of the formulated four weather criteria being satisfied predict high, moderate and low levels of thrips, respectively.

Prediction of rice yellow stem borer: Location: Raipur (Chhattisgarh): Criteria: Weather based criteria viz., maximum temperature of $31-34^{\circ} \mathrm{C}$, minimum temperature between $22 \& 23^{\circ} \mathrm{C}$ relative humidity (morning) of $89-92 \%$, rainfall $0-10 \mathrm{~mm}$ and sunshine hours of 6-9 hr/day predict the severity viz., High (>1000), Moderate (100-1000) and Low (<100) of yellow stem borer (YSB) based on light trap catches on weekly basis. Rule: More than three, three and less than three out of five weather parameters in the criteria predict high, moderate and low severity of YSB, respectively.

Location: Pattambi (Kerala): Criteria: Weather based criteria viz., maximum temperature of $31-34.5^{\circ} \mathrm{C}$, a minimum temperature of $20-21^{\circ} \mathrm{C}$, relative humidity (morning) of 85-95\%, relative humidity (evening) of 35- $50 \%$, no rainfall and sunshine hours $>8.5 \mathrm{hrs} /$ day predict the severity viz., High (>40), Moderate (20-40) and Low $(<200)$ of yellow stem borer (YSB) based on light trap catches on a weekly basis. Rule: Satisfying all six, five and four or less, out of six weather based criteria predict high, moderate and low severity of YSB, respectively (Data sets used: 2000-2007).

Location: Aduthurai (Tamil Nadu): Criteria: Weather based criteria viz., maximum temperature of $30-32^{\circ} \mathrm{C}$, a minimum temperature of $20-22^{\circ} \mathrm{C}$, relative humidity (morning) of $90-93 \%$, total rainfall $<10 \mathrm{~mm}$ and sunshine hours >8- $9 \mathrm{hrs} /$ day predict the severity viz., High (>200), Moderate (100-200) and Low $(<100)$ of yellow stem borer (YSB) based on moth catches in light traps on a weekly basis. 8-9 hrs/day predict the severity viz., High (> 200), Moderate (100-200) and Low (<100) of yellow stem borer (YSB) based on moth catches in light traps on a weekly basis. Rule: Satisfying more than three, three and two or less, out of five weather based criteria predict high, moderate and low severity of YSB.

Prediction of rice pests at Raipur (Chhattisgarh): Gall midge: Criteria: Weather based criteria viz., maximum temperature of $32-34 \mathrm{Oz}$, minimum temperature of 19 $22^{\circ} \mathrm{C}$, total rainfall of $<10 \mathrm{~mm}$, relative humidity (morning) of 89-93\% and sunshine hours of 7- 9 hrs/day predict the severity viz., High (>200), Moderate (100$200)$ and Low $(<100)$ of gall midge based on catches in light trap on a weekly basis. Rule: Satisfying all five, four and three or less, out of five weather based criteria predict high, moderate and low severity of gall midge, respectively. 


\section{International Journal of Advanced Multidisciplinary Scientific Research (IJAMSR) ISSN:2581-4281}

Combination of pests (YSB, Gallmidge, Green leaf hopper and Case worm): Criteria: Weather based criteria viz., maximum temperature of $31-34^{\circ} \mathrm{C}$, minimum temperature of $20-23^{\circ} \mathrm{C}$, total rainfall of $<10 \mathrm{~mm}$, relative humidity (morning) of $89-93 \%$ and sun shine hours of 8-9 hrs/day predict the severity viz., High (>1000), Moderate (500-1000) and Low (<500) of YSB, Gall midge and Case worm, and High (>2000), Moderate (1000-2000) and Low (<1000) of GLH based on catches in light trap on weekly basis. Rule: Satisfying four or more, three, and two or less out of five weather based criteria predict high, moderate and low severity of all pests.

Prediction of Spodoptera litura on Groundnut at Dharwad (Karnataka): Criteria: Weather based criteria viz., maximum temperature of $25-28^{\circ} \mathrm{C}$, a minimum temperature of $>19.5^{\mathrm{Oz}}$, relative humidity (morning) of $>90 \%$, relative humidity (evening) of $78-83 \%$ and rainfall $<20 \mathrm{~mm}$ predict the severity based on weekly pheromone trap catches viz., High (>400), Moderate (200-400) and Low (<200) of S. litura. Rule: Satisfying all five, four and three or less, out of five weather based criteria predict high, moderate and low severity of Spodoptera.

Validation of a prediction rule of Helicoverpa armigera in pigeonpea at Gulbarga during 2001-2010 the prediction rule was developed at NCIPM earlier (Das et al., 2001)

Population level (yearly male moth catch/ light trap)

a) High (> 2000): $\mathrm{A}^{-} \mathrm{B}^{+}$parameters satisfied
b) Moderate (1000-2000): $\mathrm{A}^{-} \mathrm{B}^{-}$or $\mathrm{A}+\mathrm{B}+$ parameters satisfied

c) Low (< 1000): $\mathrm{A}^{+} \mathrm{B}^{-}$parameters satisfied

1. Weather parameter
a. A (Rainfall during the months of June - September)
b. B (Rainfall during month of October)
c. +/- Surplus / deficit rainfall

\begin{tabular}{|c|c|c|c|c|c|c|c|c|c|}
\hline \begin{tabular}{|l|}
$\mathrm{Ye}$ \\
$\mathrm{ar}$
\end{tabular} & \begin{tabular}{|l} 
Rai \\
nfal \\
I \\
(m \\
m) \\
Jun \\
e - \\
Sep \\
t. \\
\end{tabular} & $\begin{array}{l}\text { Surplus } \\
/ \\
\text { deficit } \\
\text { Normal } \\
=580.5 \\
\mathrm{~mm}\end{array}$ & $A$ & \begin{tabular}{|l|} 
Rai \\
nfal \\
I \\
(m \\
m) \\
Oct.
\end{tabular} & $\begin{array}{l}\text { Surplus/ } \\
\text { deficit } \\
\text { Normal } \\
=81.8 \\
\mathrm{~mm}\end{array}$ & $B$ & $\begin{array}{l}\text { Predi } \\
\text { cted } \\
\text { popul } \\
\text { ation } \\
\text { level }\end{array}$ & $\begin{array}{l}\text { Obser } \\
\text { ved } \\
\text { popul } \\
\text { ation }\end{array}$ & $\begin{array}{l}\text { Obser } \\
\text { ved } \\
\text { popul } \\
\text { ation } \\
\text { level }\end{array}$ \\
\hline \begin{tabular}{l|}
20 \\
01
\end{tabular} & $\begin{array}{l}527 \\
.3\end{array}$ & -53.2 & $\begin{array}{l}A \\
-\end{array}$ & $\begin{array}{l}56 . \\
4\end{array}$ & -25.4 & $B$ & $\begin{array}{l}(\mathrm{A}-\mathrm{B}-) \\
\text { Mode } \\
\text { rate }\end{array}$ & 3218 & $\begin{array}{l}\text { Sever } \\
\text { e }\end{array}$ \\
\hline \begin{tabular}{|l|}
20 \\
03
\end{tabular} & 411 & -169.5 & A & $\begin{array}{l}14 . \\
2\end{array}$ & -67.6 & $B$ & $\begin{array}{l}(\mathrm{A}-\mathrm{B}-) \\
\text { Mode } \\
\text { rate }\end{array}$ & 1033 & $\begin{array}{l}\text { Mode } \\
\text { rate }\end{array}$ \\
\hline \begin{tabular}{|l|}
20 \\
04
\end{tabular} & $\begin{array}{l}511 \\
.2\end{array}$ & -69.3 & $\begin{array}{l}\text { A } \\
-\end{array}$ & $\begin{array}{l}121 \\
.2\end{array}$ & 39.4 & $B$ & $\begin{array}{l}(\mathrm{A}-\mathrm{B}+ \\
\text { Seve } \\
\text { re }\end{array}$ & 1130 & $\begin{array}{l}\text { Mode } \\
\text { rate }\end{array}$ \\
\hline \begin{tabular}{|l|}
20 \\
05 \\
\end{tabular} & $\begin{array}{l}626 \\
.4 \\
\end{array}$ & 45.9 & $\begin{array}{l}\text { A } \\
+ \\
\end{array}$ & $\begin{array}{l}67 . \\
5 \\
\end{array}$ & -14.3 & $B$ & $\begin{array}{l}(A+B- \\
\text { Low }\end{array}$ & 793 & Low \\
\hline \begin{tabular}{l|}
20 \\
06
\end{tabular} & $\begin{array}{l}338 \\
.3\end{array}$ & -242.2 & $\begin{array}{l}\text { A } \\
-\end{array}$ & $\begin{array}{l}37 . \\
4\end{array}$ & -44.4 & $B$ & $\begin{array}{l}(\mathrm{A}-\mathrm{B}-) \\
\text { Mode } \\
\text { rate }\end{array}$ & 1062 & $\begin{array}{l}\text { Mode } \\
\text { rate }\end{array}$ \\
\hline \begin{tabular}{|l|}
20 \\
07 \\
\end{tabular} & $\begin{array}{l}710 \\
.6 \\
\end{array}$ & 130.1 & $\begin{array}{l}\text { A } \\
+ \\
\end{array}$ & $\begin{array}{l}14 . \\
7\end{array}$ & -67.1 & B & $\begin{array}{l}(A+B-) \\
\text { Low }\end{array}$ & 751 & Low \\
\hline \begin{tabular}{|l|}
20 \\
08
\end{tabular} & $\begin{array}{l}486 \\
.4\end{array}$ & -94.1 & A & $\begin{array}{l}74 . \\
4\end{array}$ & -7.4 & $B$ & $\begin{array}{l}(A-B+ \\
\text { Sever } \\
\text { e }\end{array}$ & 1268 & $\begin{array}{l}\text { Mode } \\
\text { rate }\end{array}$ \\
\hline \begin{tabular}{l|}
20 \\
09
\end{tabular} & $\begin{array}{l}681 \\
.2\end{array}$ & 100.7 & $\begin{array}{l}\text { A } \\
+\end{array}$ & $\begin{array}{l}180 \\
.1\end{array}$ & 98.3 & $\begin{array}{l}B \\
+\end{array}$ & $\begin{array}{l}(\mathrm{A}+\mathrm{B}+ \\
\text { Mode } \\
\text { rate }\end{array}$ & 773 & Low \\
\hline \begin{tabular}{|l|}
20 \\
10 \\
\end{tabular} & 746 & 165.5 & $A$ & $\begin{array}{l}87 . \\
6\end{array}$ & 5.8 & B & $\begin{array}{l}(A+B- \\
\text { Low }\end{array}$ & 122 & Low \\
\hline
\end{tabular}




\section{International Journal of Advanced Multidisciplinary Scientific Research (IJAMSR) ISSN:2581-4281}

The thumb rule developed earlier by (Das et al (2001) at NCIPM was validated with the weather and light trap catch (moth) data during 2001-10. Out of 10 years, the prediction was perfectly alright for 6 years. In other years, there was one level deviation. Except the year 2001-02, observed level was one scale lower than predicted one and the results were used without any harm.

\section{Climate change and changing scenario of pathogens}

Climate change may affect plant pathosystems at various levels viz. from genes to populations and from ecosystem to distributional ranges; from environmental conditions to host vigour to susceptibility; and from pathogen virulence to infection rates. Climate change is likely to have a profound effect on geographical distribution of host and pathogens, changes in the physiology of host-pathogen interactions, changes in the rate of development of the pathogens e.g., increased oversummering and overwintering of pathogens, increased transmission and dispersal of pathogens and the emergence of new diseases. Similarly, prolonged moisture may create a new scenario of potential diseases in SAT crops, such as anthracnose, collar rot, wet root rot, and stunt diseases in chickpea; to Phytophthora blight, Alternaria blight in pigeonpea, leaf spots and rusts in groundnut, blast and rust in pearl millet, leaf blight and grain mold complex in sorghum.

Efforts are underway across laboratories to forecast the changing scenarios of pathogens and diseases of SAT crops under variable climatic conditions through simulation modeling and targeted surveys. Studies are also being initiated to understand the behavior of the vectors of pathogens from the point of view epidemic development as well as Biosecurity Pande et. al 2010.

\section{Climate change and crop disease}

Climate factors that influence the growth, spread, and survival of crop diseases include temperature, precipitation, humidity, dew, radiation, wind speed, circulation patterns, and the occurrence of extreme events. Most analyses conclude that in a changing climate, pests may become even more active than they currently are, thus posing the threat of greater economic losses to farmers (Coakley et al., 1999). Higher temperature, humidity and greater precipitation, on the other hand, are likely to result in the spread of plant diseases, as wet vegetation promotes the germination of spores and the proliferation of bacteria and fungi, besides influencing the life cycle of soil nematodes and other organisms.

\section{Effect of elevated $\mathrm{CO}_{2}$ on crop disease dynamics}

1. Both enhancement and reduction in disease severity under elevated $\mathrm{CO}_{2}$ has been reported. Elevated $\mathrm{CO}_{2}$ would increase canopy size and density of plants, resulting in a greater biomass production and microclimates may become more conducive for rusts, mildews, leaf spots and blight development. Decomposition of plant litter is important for nutrient 


\section{International Journal of Advanced Multidisciplinary Scientific Research (IJAMSR) ISSN:2581-4281}

cycling and in the saprophytic survival of many pathogens. Because of high $\mathrm{C}$ : $\mathrm{N}$ ratio of litter as a consequence of plant growth under elevated $\mathrm{CO}_{2}$, decomposition will be slower. Increased plant biomass, slower decomposition of litter, and higher winter temperature could increase pathogen survival on over-wintering crop residues and increase the amount of initial inoculation available for subsequent infection.

2. Some fungal pathosystems under elevated $\mathrm{CO}_{2}$ revealed two important trends. First, delay in the initial establishment of the pathogen because of modifications in pathogen aggressiveness and/or host susceptibility. For example, reduction in the rate of primary penetration of Eysiphe graminis on barley and a lengthening of latent period in Maravalia cryptostegiae (rubervine rust) has been observed under elevated $\mathrm{CO}_{2}$. Here, host resistance may have increased because of changes in host morphology, physiology, nutrients and water balance. A decrease in stomatal density increases resistance to pathogens that penetrate through stomata. Under elevated $\mathrm{CO}_{2}$ barley plants were able to mobilize assimilates into defense structures, including the formation of papillae and accumulation of silicon at sites of appressorial penetration of Erysiphe graminis.

3. At elevated $\mathrm{CO}_{2}$, increased partitioning of assimilates to roots occurs consistently in crops such as carrot, sugar beet, and radish. If more carbon is stored in the roots, losses from soil-borne diseases of root crops may be reduced under climate change. In contrast, for foliage diseases favored by high temperature and humidity, increases in temperature and precipitation under climate change may result in increased crop loss. The effects of enlarged plant canopies of elevated $\mathrm{CO}_{2}$ could further increase crop losses from foliar pathogens.
4. The second important effect is an increase in the fecundity of pathogens under elevated $\mathrm{CO}_{2}$. Following penetration, established colonies of Erysiphe graminis grew faster and sporulation per unit area of infected tissue was increased several-fold under elevated $\mathrm{CO}_{2}$. It has been also observed that under elevated $\mathrm{CO}_{2}$ out of the 10 biotrophic pathogens studied, disease severity was enhanced in six and reduced in four and out of 15 necrotrophic pathogens, disease severity increased in nine, reduced in four and remained unchanged in the other two.

A preliminary study also showed that hot and comparatively dry conditions were favorable for ricehispa incidences while a decrease in minimum temperature under humid and cloudy condition caused the incidences of rice blast. Working with tikka disease infestation of groundnut, it is observed that decrease in maximum and minimum temperature below $32^{\circ} \mathrm{C}$ and $19^{\circ} \mathrm{C}$ respectively, and increase in the morning and afternoon relative humidity above $90 \%$ and $80 \%$ respectively favoured the infestation of tikka disease of groundnut. Similarly increase in maximum temperature was found to increase the infestation of both fruit canker of guava and early blight of tomato. Decrease in afternoon relative humidity favored the infestation of fruit canker of guava and rust of fig. Fall of minimum temperature and rise in bright hours of sunshine also aggravated the incidence of fruit canker of guava and rust. 


\section{International Journal of Advanced Multidisciplinary Scientific Research (IJAMSR) ISSN:2581-4281}

Table 4Effect of increased $\mathrm{CO}_{2}$ concentrations of pathogens

\begin{tabular}{|c|c|c|}
\hline Author & Study & Effect \\
\hline $\begin{array}{l}\text { Hibberd et al. } \\
\text { (1996) }\end{array}$ & $\begin{array}{l}\text { The effect of elevated } \\
\text { concentrations of } \\
\mathrm{CO}_{2} \text { on the infection } \\
\text { of barley by Erysiphe } \\
\text { graminis was } \\
\text { determined. }\end{array}$ & 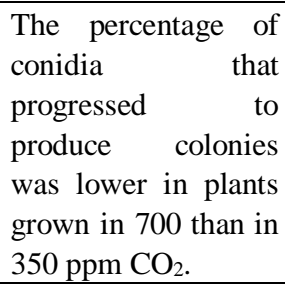 \\
\hline $\begin{array}{l}\text { Tiedemann } \\
\text { and } \\
\text { Firstching } \\
\text { (2000). }\end{array}$ & $\begin{array}{l}\text { Interactive effects of } \\
\text { elevated } \mathrm{CO}_{2} \text { and } \mathrm{O}_{3} \\
\text { levels on wheat } \\
\text { leaves infected with } \\
\text { leaf rust fungus } \\
\text { Puccinia triticina } \\
\text { were described. }\end{array}$ & $\begin{array}{l}\text { Elevated } \mathrm{CO}_{2} \\
\text { increased the } \\
\text { photosynthetic rates } \\
\text { of the diseased } \\
\text { plants by } 20 \text { and } \\
42 \% \text { at the ambient } \\
\text { and elevated ozone } \\
\text { concentrations, } \\
\text { respectively. }\end{array}$ \\
\hline $\begin{array}{l}\text { Jwa and } \\
\text { Walling } \\
(2001) \text {. }\end{array}$ & $\begin{array}{l}\text { The effects of } \\
\text { elevated } \\
\text { concentrations on the } \\
\text { development of } \\
\text { Phytophthora } \\
\text { parasitica (root rot) } \\
\text { in tomato were } \\
\text { evaluated. }\end{array}$ & $\begin{array}{l}\text { The extra } \mathrm{CO}_{2} \\
\text { completely } \\
\text { counterbalanced the } \\
\text { negative effect of the } \\
\text { pathogenic infection } \\
\text { on overall plant } \\
\text { productivity. }\end{array}$ \\
\hline $\begin{array}{l}\text { Chakraborty } \\
\text { et al. } \\
(2002) \text {. }\end{array}$ & $\begin{array}{l}\text { The germination rates } \\
\text { of conidia of } C \text {. } \\
\text { gloeosporioides were } \\
\text { determined. }\end{array}$ & $\begin{array}{l}\text { Spore germination } \\
\text { was reduced and } \\
\text { extended incubation } \\
\text { period was at } 700 \\
\text { ppm, and } \\
\text { Anthracnose severity } \\
\text { was reduced. }\end{array}$ \\
\hline $\begin{array}{l}\text { Karnosky et } \\
\text { al. } \\
(2002) .\end{array}$ & $\begin{array}{l}\text { Elevated } \mathrm{CO}_{2} \text { and } \\
\text { tropospheric } \mathrm{O}_{3} \\
\text { concentrations were } \\
\text { related to infection } \\
\text { by rust (Melampsora } \\
\text { medusae f. sp } \\
\text { tremuloidae) in aspen } \\
\text { (Populus tremuloides } \\
\text { Michx.) }\end{array}$ & $\begin{array}{l}\text { Three- to five-fold } \\
\text { increases in levels of } \\
\text { rust infection index } \\
\text { were found. }\end{array}$ \\
\hline $\begin{array}{l}\text { Pangga et al. } \\
\text { (2004). }\end{array}$ & $\begin{array}{l}\text { The relative } \\
\text { importance of canopy } \\
\text { size and induced } \\
\text { resistance to } \\
\text { Colletotrichum } \\
\text { gloeosporioides was } \\
\text { examined at } \\
\text { atmospheric } \mathrm{CO}_{2} \\
\text { concentrations of } 350\end{array}$ & $\begin{array}{l}\text { Up to twice as many } \\
\text { lesions per plant } \\
\text { were produced in the } \\
\text { high } \mathrm{CO}_{2} \text { plants, } \\
\text { because the enlarged } \\
\text { canopy trapped } \\
\text { many more } \\
\text { pathogen spores. }\end{array}$ \\
\hline
\end{tabular}

\begin{tabular}{|c|c|c|}
\hline & $\begin{array}{l}\text { and } 700 \text { ppm. } \\
\text { Susceptible } \\
\text { Stylosanthes scabra } \\
\text { (Fitzroy) in a } \\
\text { evaluated in ace } \\
\text { controlled } \\
\text { environment facility } \\
\text { (CEF) and the field. }\end{array}$ & \\
\hline $\begin{array}{l}\text { Kobayashi et } \\
\text { al. } \\
(2006) \text {. }\end{array}$ & $\begin{array}{lr}\text { Pyricularia } & \text { oryzae } \\
\text { Cavara } & \text { and } \\
\text { Rhizoctonia } & \text { solani } \\
\text { Kühn were evaluated. }\end{array}$ & $\begin{array}{l}\text { Rice plants grown in } \\
\text { an elevated } \mathrm{CO}_{2} \\
\text { concentration were } \\
\text { more susceptible to } \\
\text { leaf blast than those } \\
\text { in ambient } \mathrm{CO}_{2} \text {. }\end{array}$ \\
\hline $\begin{array}{l}\text { Eastburn et } \\
\text { al. } \\
(2010) .\end{array}$ & $\begin{array}{l}\text { The effects of carbon } \\
\text { dioxide }\left(\mathrm{CO}_{2}\right) \text { and } \\
\text { ozone }\left(\mathrm{O}_{3}\right) \text { on three } \\
\text { soybean diseases } \\
\text { (downy mildew, } \\
\text { Septoria and sudden } \\
\text { death syndrome) } \\
\text { were determined in } \\
\text { the field. }\end{array}$ & $\begin{array}{lr}\text { Changes } & \text { in } \\
\text { atmospheric } & \\
\text { composition } & \text { altered } \\
\text { disease } & \text { expression. } \\
\text { Elevated } & \mathrm{CO}_{2} \\
\text { reduced } & \text { downy } \\
\text { mildew } & \text { disease } \\
\text { severity. } & \text { But } \\
\text { increased brown spot } \\
\text { severity and without } \\
\text { effect in sudden } \\
\text { death syndrome. } \\
\end{array}$ \\
\hline $\begin{array}{l}\text { Strengbom } \\
\text { and } \\
\text { Reich (2006). }\end{array}$ & $\begin{array}{l}\text { The incidence of leaf } \\
\text { spot on mature leaves } \\
\text { of Solidago rigida } \\
\text { was assessed. The } \\
\text { incidence of disease } \\
\text { was reduced by half } \\
\text { under } \mathrm{ECO}_{2} \\
\text { concentrations. }\end{array}$ & $\begin{array}{l}\text { Disease incidence } \\
\text { was lower in plots } \\
\text { with either elevated } \\
{\left[\mathrm{CO}_{2}\right] \text { or enriched } \mathrm{N}} \\
(-57 \text { and }-37 \% \text {, } \\
\text { respectively) than in } \\
\text { plots with ambient } \\
\text { conditions. }\end{array}$ \\
\hline $\begin{array}{l}\text { Matros et al. } \\
(2006) .\end{array}$ & $\begin{array}{l}\text { The response } \text { of } \\
\text { tobacco to potato } \\
\begin{array}{l}\text { virus Y } \\
\text { evaluated. }\end{array}\end{array}$ & $\begin{array}{l}\text { The titre of viral } \\
\text { coat-protein was } \\
\text { markedly reduced in } \\
\text { leaves under these } \\
\text { conditions at both } \\
\text { nitrogen levels. The } \\
\text { accumulation of } \\
\text { phenylpropanoids, } \\
\text { may result in an } \\
\text { earlier confinement } \\
\text { of the virus at high } \\
\mathrm{CO}_{2} \text {. }\end{array}$ \\
\hline $\begin{array}{l}\text { Lake and } \\
\text { Wade } \\
(2009) .\end{array}$ & $\begin{array}{l}\text { Interactions between } \\
\text { Erysiphe } \\
\text { cichoracearum and } \\
\text { Arabidopsis thaliana } \\
\text { under elevated levels } \\
\text { of } \mathrm{CO} 2 \text { were } \\
\text { assessed. }\end{array}$ & $\begin{array}{l}\text { The number of } \\
\text { established colonies } \\
\text { (networks of } \\
\text { mycelia) on mature } \\
\text { leaves increased } \\
\text { significantly }\end{array}$ \\
\hline
\end{tabular}


https://doi.org/10.31426/ijamsr.2018.1.10.1012

\section{International Journal of Advanced Multidisciplinary Scientific Research (IJAMSR) ISSN:2581-4281}

\begin{tabular}{|c|c|c|}
\hline $\begin{array}{l}\text { Runion et al. } \\
\text { (2010). }\end{array}$ & $\begin{array}{l}\text { The effects of } \\
\text { elevated atmospheric } \\
\mathrm{CO}_{2} \text { concentrations } \\
\text { on two southern } \\
\text { forest diseases } \\
\text { (Cronartium } \\
\text { quercuum and } \\
\text { Fusarium circinatum) } \\
\text { were assessed. }\end{array}$ & $\begin{array}{l}\text { In general, disease } \\
\text { incidence was } \\
\text { decreased by } \\
\text { exposure to elevated } \\
\mathrm{CO}_{2} \text {, and increased } \\
\text { the latent period } \\
\text { (time to sporulation) } \\
\text { for fusiform rust on } \\
\text { red oak seedlings. }\end{array}$ \\
\hline $\begin{array}{l}\text { Shin and Yun } \\
\text { (2010) }\end{array}$ & 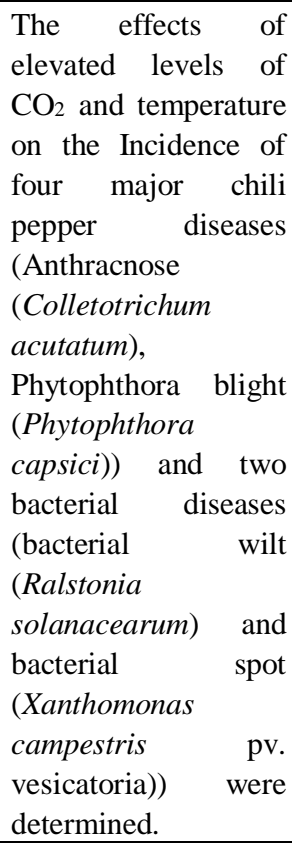 & $\begin{array}{l}\text { Elevated } \mathrm{CO}_{2} \text { and } \\
\text { temperature } \\
\text { significantly } \\
\text { increased the } \\
\text { incidence of two } \\
\text { bacterial diseases. } \\
\text { Anthracnose } \\
\text { decreased and } \\
\text { Phytophthora blight } \\
\text { slightly increased. }\end{array}$ \\
\hline $\begin{array}{l}\text { McElrone et } \\
\text { al. } \\
(2010)\end{array}$ & $\begin{array}{l}\text { Effect of elevated } \\
\mathrm{CO}_{2} \text { and inter annual } \\
\text { climatic variability } \\
\text { affect Cercospora } \\
\text { leaf spot diseases of } \\
\text { two deciduous trees }\end{array}$ & $\begin{array}{l}\text { When significant } \\
\text { changes did occur, } \\
\text { disease incidence } \\
\text { and severity always } \\
\text { increased under } \\
\text { elevated } \mathrm{CO}_{2} \text {. }\end{array}$ \\
\hline
\end{tabular}

Role of Indian metrological department for forewarning of crop disease intensities

\begin{tabular}{|c|c|c|c|c|}
\hline $\begin{array}{l}\text { Crop/ } \\
\text { Diseas } \\
\text { e }\end{array}$ & Station & $\begin{array}{l}\text { Period } \\
\text { of } \\
\text { damag } \\
\text { e }\end{array}$ & $\begin{array}{l}\text { Stage of } \\
\text { the crop }\end{array}$ & $\begin{array}{l}\text { Congenial } \\
\text { weather } \\
\text { condition }\end{array}$ \\
\hline $\begin{array}{l}\text { Rice/ } \\
\text { Blast }\end{array}$ & $\begin{array}{l}\text { Maharash } \\
\text { tra and } \\
\text { Karnatak } \\
\text { a }\end{array}$ & $\begin{array}{l}\text { August } \\
\text { to } \\
\text { Januar } \\
\text { y }\end{array}$ & $\begin{array}{l}\text { Tillering } \\
\text { to } \\
\text { Maturity }\end{array}$ & $\begin{array}{l}\mathrm{T}_{\min }< \\
23.5^{\circ} \mathrm{C} \\
\mathrm{Rh}_{1}>90 \% \\
\mathrm{Rh}_{2}>80 \% \\
\text { Partly }\end{array}$ \\
\hline
\end{tabular}

\begin{tabular}{|c|c|c|c|c|}
\hline & & & & clouding \\
\hline $\begin{array}{l}\text { Groun } \\
\text { dnut / } \\
\text { Tikka }\end{array}$ & $\begin{array}{l}\text { Warangal } \\
\text { Hyderaba } \\
\text { d } \\
\text { Nagpur } \\
\text { Anand }\end{array}$ & & & \\
\hline Rust & $\begin{array}{l}\text { Akola } \\
\text { (Maharas } \\
\text { htra) } \\
\text { /Central } \\
\text { Vidarbha }\end{array}$ & $\begin{array}{l}\text { Septem } \\
\text { ber \& } \\
\text { Octobe } \\
r\end{array}$ & $\begin{array}{l}\text { Pod } \\
\text { ripening }\end{array}$ & $\begin{array}{l}\text { Tmin < } \\
16.30 \mathrm{C} \mathrm{Rh} 1 \\
: 20-40 \% \\
\text { Rh2 :50- } \\
95 \% \text { Ssh > } \\
7.5 \text { hrs. }\end{array}$ \\
\hline Tikka & $\begin{array}{c}\text { Warangal } \\
\text { Hyderaba } \\
\text { d } \\
\text { Nagpur } \\
\text { Anand } \\
\end{array}$ & $\begin{array}{l}\text { Kharif } \\
\text { Rabi }\end{array}$ & $\begin{array}{c}\text { Pod } \\
\text { formatio } \\
n \\
\text { to } \\
\text { maturity }\end{array}$ & $\begin{array}{l}\mathrm{Tmax}<30^{\circ} \\
\mathrm{C} \\
\mathrm{Rh}_{1}>80 \% \\
\mathrm{Rh}_{2}>60 \% \\
\text { Clouding } \\
\text { condition }\end{array}$ \\
\hline & $\begin{array}{c}\text { Ahmedab } \\
\text { ad } \\
\text { Anand } \\
\text { Bhavnag } \\
\text { ar } \\
\text { Jamnagar } \\
\text { Junagarh } \\
\text { Veraval } \\
\text { (Gujrat) }\end{array}$ & -- & $\begin{array}{c}\text { Pod } \\
\text { formatio } \\
n \\
\text { to } \\
\text { Pod } \\
\text { develop } \\
\text { ment }\end{array}$ & $\begin{array}{l}\text { Tmax }< \\
34{ }^{0} \mathrm{C} \\
\mathrm{Tmin}< \\
22{ }^{\circ} \mathrm{C} \\
\mathrm{Rh}_{1}>82 \% \\
\mathrm{Rh}_{2}>78 \% \\
\text { Clouding }\end{array}$ \\
\hline & $\begin{array}{c}\text { Akola } \\
\text { (Maharas } \\
\text { htra) } \\
\text { /Central } \\
\text { Vidarbh }\end{array}$ & $\begin{array}{l}\text { July to } \\
\text { Octobe } \\
\quad r \\
\text { (mere } \\
\text { in } \\
\text { Octobe } \\
\text { r) }\end{array}$ & ---- & $\begin{array}{l}\text { i) Low } \\
\text { range of } \\
\text { day -night } \\
\text { temperature } \\
\text { ii) Less } \\
\text { sunshine } \\
\text { hours } \\
\text { iii) Increase } \\
\text { in rainfall } \\
\text { (July) } \\
\text { iv) Fall in } \\
\text { Tmean } \\
\text { in 1st } \\
\text { fortnight of } \\
\text { August }\end{array}$ \\
\hline
\end{tabular}

Sources: India Meteorological Department (IMD)

Other sources for forewarning of crop pest 
https://doi.org/10.31426/ijamsr.2018.1.10.1012

I J A M S R

\section{International Journal of}

Advanced Multidisciplinary Scientific Research (IJAMSR) ISSN:2581-4281

Table 3 Weather parameters related to Phytophthora infestans

\begin{tabular}{|l|l|l|}
\hline Source & $\begin{array}{l}\text { Temperature } \\
\text { condition }\end{array}$ & $\begin{array}{l}\text { Humidity } \\
\text { condition }\end{array}$ \\
\hline $\begin{array}{l}\text { (Beaumont, } \\
1947)\end{array}$ & $>10^{\circ} \mathrm{C}$ & $>75 \%$ \\
\hline $\begin{array}{l}\text { Smith, } \\
1956)\end{array}$ & $>10^{\circ} \mathrm{C}$ & $\begin{array}{l}>90 \% \text { for }>11 \\
\text { hours }\end{array}$ \\
\hline $\begin{array}{l}\text { (Hyre, 1954) } \\
\text { for last five days }\end{array}$ & $\begin{array}{l}\text { Total rainfall } \\
>3 \mathrm{~cm} \text { for last 10 } \\
\text { days }\end{array}$ \\
\hline $\begin{array}{l}\text { (Duniway, } \\
1983)\end{array}$ & $\begin{array}{l}>3^{\circ} \mathrm{C}- \\
\text { longer than } 8 \text { hours }\end{array}$ & $\begin{array}{l}100 \% \text { relative } \\
\text { humidity for } 8 \\
\text { hours }\end{array}$ \\
\hline
\end{tabular}

Table 4 Weather parameters related to Fusarium head blight graminearum

\begin{tabular}{|l|l|l|}
\hline Source & $\begin{array}{l}\text { Temperature } \\
\text { condition }\end{array}$ & Humidity condition \\
\hline $\begin{array}{l}\text { (Pugh } \text { et al., } \\
1933)\end{array}$ & $25^{\circ} \mathrm{C}$ & $\begin{array}{l}\text { Continuous wetness for } \\
48 \text { hours relates to } 77 \% \\
\text { infection }\end{array}$ \\
\hline $\begin{array}{l}\text { (Cook and } \\
\text { Christen, } \\
1976)\end{array}$ & $20^{\circ} \mathrm{C}-30^{\circ} \mathrm{C}$ & Substrate is moist \\
\hline $\begin{array}{l}\text { (Lacey et } \\
\text { al., 1999) }\end{array}$ & $>9^{\circ} \mathrm{C}-<26^{\circ} \mathrm{C}$ & \\
\hline
\end{tabular}

Favorable condition for crop disease in rice crop

\begin{tabular}{|l|l|}
\hline $\begin{array}{l}\text { Crop } \\
\text { diseases }\end{array}$ & Favorable condition \\
\hline Rice blast & $\begin{array}{l}\text { Application of excessive doses of } \\
\text { nitrogenous fertilizers, intermittent } \\
\text { drizzles cloudy weather, high } \\
\text { relative humidity (93-99 per cent), } \\
\text { low night temperature (between 15- } \\
\text { 20 } \mathrm{C}), \text { more number of rainy days, } \\
\text { longer duration of dew, cloudy } \\
\text { weather, slow wind movement and } \\
\text { availability of collateral hosts. }\end{array}$ \\
\hline Brown & \begin{tabular}{l} 
Temperature of $25-30^{\circ} \mathrm{C}$ with \\
\hline
\end{tabular} \\
\hline
\end{tabular}

\begin{tabular}{|l|l|}
\hline spot & $\begin{array}{l}\text { relative humidity above } 80 \text { per cent } \\
\text { is highly favorable. Excess of } \\
\text { nitrogen aggravates the disease } \\
\text { incidence. }\end{array}$ \\
\hline $\begin{array}{l}\text { Sheath } \\
\text { rot }\end{array}$ & $\begin{array}{l}\text { Closer planting, high doses of } \\
\text { nitrogen, high humidity and } \\
\text { temperature around 25-30 C. } \\
\text { Injuries made by leaf folder, brown } \\
\text { plant hopper and mites increase } \\
\text { infection }\end{array}$ \\
\hline $\begin{array}{l}\text { Sheath } \\
\text { blight }\end{array}$ & $\begin{array}{l}\text { High relative humidity }(96-97 \text { per } \\
\text { cent), high temperature }\left(30-32^{\circ} \mathrm{C}\right), \\
\text { closer planting and heavy doses of } \\
\text { nitrogenous fertilizers }\end{array}$ \\
\hline $\begin{array}{l}\text { False } \\
\text { smut }\end{array}$ & $\begin{array}{l}\text { Rainfall and cloudy weather during } \\
\text { the flowering and maturity periods } \\
\text { are favorable. }\end{array}$ \\
\hline $\begin{array}{l}\text { Bacterial } \\
\text { leaf } \\
\text { blight }\end{array}$ & $\begin{array}{l}\text { Clipping of tip of the seedling at } \\
\text { the time of transplanting, heavy } \\
\text { rain, heavy dew, flooding, deep } \\
\text { irrigation water, severe wind, and } \\
\text { temperature of 25-30 }{ }^{\circ} \mathrm{C} \text { and } \\
\text { application of excessive nitrogen, } \\
\text { especially late top dressing }\end{array}$ \\
\hline
\end{tabular}

Sources P. Raja and R. Saravanan integrated diseases management in paddy, college of horticulture and forestry, central agricultural university, Pasighat East Siang district, Arunachal Pradesh.

Relationship between diseases and weather condition in groundnut

Several diseases causing large losses in both yield and quality of seeds affect the agricultural crop. Weather indirectly influences the yield and quality through its effects on the occurrence and development of diseases.

Kolte (1985) reviewed diseases of groundnut in relation to weather conditions. Early and late leaf spots 


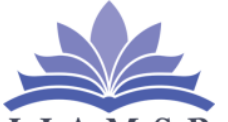

I J A M S R

International Journal of

Advanced Multidisciplinary Scientific Research (IJAMSR) ISSN:2581-4281

(Cercospora arachidicola and Puccinia personate) are considered the most important diseases of groundnut. They have been reported throughout the groundnutgrowing areas of the world. Leaf spots cause huge yield loss in groundnut due to severe defoliation. Weather conditions conducive to the occurrence of early and late leaf spots as reported by different researchers are summarized in Table 10.2.6, which basically conveys that rainfall, leaf wetness and temperature are the most important factors for the occurrence and epidemiology of leaf spots.

\begin{tabular}{|c|c|c|}
\hline Disease & $\begin{array}{l}\text { Favorable weather } \\
\text { condition }\end{array}$ & References \\
\hline \multirow[t]{3}{*}{ Rust } & $\begin{array}{l}\text { In India, a continuous } \\
\text { dry period characterized } \\
\text { by high temperature } \\
\left(>26^{\circ} \mathrm{C}\right) \text { and low relative } \\
\text { humidity ( }<70 \text { per cent) } \\
\text { is reported to delay rust } \\
\text { occurrence and severity, } \\
\text { whereas intermittent rain, } \\
\text { high relative humidity } \\
\text { and } 20^{\circ} \mathrm{C} \text { to } 26^{\circ} \mathrm{C} \\
\text { temperature }\end{array}$ & $\begin{array}{l}\text { (Siddaramaiah } \\
\text { et al., 1980) }\end{array}$ \\
\hline & $\begin{array}{l}\text { In the Parbhani region of } \\
\text { Maharashtra, India, } \\
\text { observed that if average } \\
\text { temperature of } 20^{\circ} \mathrm{C}- \\
22^{\circ} \mathrm{C} \text {, relative humidity } \\
\text { above } 85 \text { per cent and } \\
\text { three rainy days in a } \\
\text { week prevail for two } \\
\text { weeks, an outbreak of } \\
\text { rust is likely. }\end{array}$ & Mayee (1987) \\
\hline & $\begin{array}{l}\text { rainfall of about } 200 \\
\text { mm, temperature } \\
\text { between } 23.5^{\circ} \mathrm{C} \text { and } \\
29.4^{\circ} \mathrm{C} \text {, and relative } \\
\text { humidity in the range of } \\
67 \text { to } 84 \text { per cent }\end{array}$ & $\begin{array}{l}\text { Lokhande et } \\
\text { al. (1998) }\end{array}$ \\
\hline $\begin{array}{l}\text { Sclerotinia } \\
\text { Blight }\end{array}$ & $\begin{array}{l}\text { Optimum temperature } \\
20^{\circ} \mathrm{C} \text { and } 25^{\circ} \mathrm{C}\end{array}$ & $\begin{array}{l}\text { (Dow et al., } \\
\text { 1988). }\end{array}$ \\
\hline \multirow[t]{2}{*}{ Collar rot } & $\begin{array}{l}\text { High soil and air } \\
\text { temperatures }\end{array}$ & (Kolte, 1985). \\
\hline & $\begin{array}{l}\text { Temperature } 31^{\circ} \mathrm{C} \text { to } \\
35^{\circ} \mathrm{C}\end{array}$ & $\begin{array}{l}\text { (Chohan, } \\
\text { 1969). }\end{array}$ \\
\hline
\end{tabular}

\section{Conclusion:}

Every year crops are being damaged by pests and diseases. Due to lack of proper operational forecasting system for the incidences of pests and diseases, it becomes difficult to adopt a plant protection measures at the right time. Weather based pest and disease forewarning provides opportunity to farmers for preparedness and for taking timely action to apply bioagents and pesticides which ultimately cut down the cost of production. On the basis of current review paper, we have concluded forewarning crop pest and disease outbreak and intensities is an important technique under the climate change scenario. In this study, we find out the congenial weather for the outbreak and intensities of crop pest and disease which is helpful for a reduction of chemical use and increases the crop yield. Some scientist who suggests the harmful effect of climate change in future, such as migration of pest and disease in northward, increase the number of generation and plant become more susceptible to crop pest and disease which can help long term future planning for crop pest and disease management.

\section{References}




\section{International Journal of Advanced Multidisciplinary Scientific Research (IJAMSR) ISSN:2581-4281}

1) Awmack, C.S., Woodcock, C.M. and Harrington, R. 1997. Climate change may increase vulnerability of aphids to natural enemies. Ecol. Entomol. 22: 366-368.

2) Bale, J.S., Masters, G.L. and Hodkinson, I.D. 2002. Herbivory in global climate change research: Directeffect of risising temperature on insect herbivorous .Global climate change Biol. 8: $1-16$.

3) Beaumont, A. 1947 The dependence on the weather of the dates of potato blight epidemics British Mycological Society 31

4) Bezemer, T.M., Jones, T.H. and Knight, K.I. 1999. Long-term effects on elevated carbon dioxide and temperature on peach aphid myzus persicae and its parasitoids Aphidium matricariae. Oecologia (Berl) 116: 128-35.

5) Cannon, R.J.C. 1998. The implications of predicted climate change for insect-pests in the UK, with emphasis on non-indigenous species, Global Change Biol. 4, 785-796

6) Chakraborty S, Murray G and White N 2002. Impact of Climate Change on Important Plant Diseases in Australia. A report for the Rural Industries Research and Development Corporation. RIRDC Publication No W02/010. RIRDC Project No CST-4A.

7) Chakraborty, S.2005. Potential impact of climate change on plant pathogen interaction Australasian plant pathology 34 443-448

8) Chattopadhyay N., R. P. Samui, L. S. Rathore 2011Strategies for Minimizing Crop Loss due to Pest and Disease Incidences by Adoption of Weather-Based Plant Protection Techniques Challenges and Opportunities in Agrometeorology , pp 235-243

9) Chen, F.G.F. and Parajulee, M.N. 2005. Impact of elevated $\mathrm{CO}_{2}$ on tritrophic interaction of Gossypium hirsutum, Aphid gossypi and Leis axyridis. Env. Entomol. 34: 37-46.

10) Cook, R.J. and Christen, A.A. 1976. Growth of cereal root rot fungi as affected by temperaturewater potential interactions. Phytopathology 66, 193-197.

11) Coviella, C., Margon, D.J.W and Trumble, J.T. 2000. Interaction of elevated $\mathrm{CO} 2$ and nitrogen fertilization:Effect on the production of Bacillus thuringiensis toxins in transgenic plants. Env. Entomol. 29: 281-7.

12) Coviella, C.E., Trumble, J.T. 1999. Effects of Elevated Atmospheric Carbon Dioxide on Insect-Plant interactions, Conserv. Biol. 13, 700-712
13) Das D K, Trivedi TP and Srivastava C P.2001.Simple rule to prediction attach of Helicoverpa armigera on crop growing in Andhra Pradesh. Indian Journal of Agricultural Science 71 (6): 421-30.

14) Dhawan, A.K., Singh, K., Saini, S., Mohindru, B., kaur, A., Singh, G. and Singh, S.2007. Incidence and damage potential of mealybug, Phenacoccus solenopsis Tinsley, on cotton in Punjab Indian J. Ecol., 34, 110-116

15) Diffenbaugh, N.S., Krupke, C.H., White, M.A. and Alexander, C.E.2008. Global warming presents new challenges for maize pest management. Env.Res. Letter, 3, 1-9

16) Dukes, J.S. and Mooney, H.A. 1999. Does global change increase the success of biological invaders? Trends Ecol. Evol. 14: 135-9.

17) Duniway, J.M. 1983. Role of physical factors in the development of phytophthora diseases. In

18) Phytophthora: its biology, taxonomy, ecology and pathology (D.C. Erwin, S. Bartnicki-Garcia \& P.H. Tsao, eds.), The American Phytopathological Society, St. Paul, Minnesota.

19) Eastburn DM, Degennaro MM, Delucia EH, Dermody O and Mcelrone AJ 2010. Elevated atmospheric carbon dioxide and ozone alter soybean diseases at SoyFACE. Global Change Biol. 16: 320-330.

20) Eastburn DM, Degennaro, MM, Delucia EH, Dermody O and Mcelrone AJ 2010. Elevated atmospheric carbon dioxide and ozone alter soybean diseases at SoyFACE. Global Change Biol. 16: 320-330.

21) Epstein, P.R., Diaz, H.F., Flias, S. 1998. Biological and physical sign of climate change: Focus Mosquito- borne diseases. Bull. Am. Meteorol. Soc. 79: 409-17.

22) Erasmus, B.F.N., Van Jarsveld, A.S. and Chown, S. 2002. Vulnerability of south Africa animal taxa on climate change. Global Change Boil.6: 679-93.

23) Fleming, R.A. and Volney, W.J.A. 1995. Effect of climate change on insect defoliator population

24) Hance, T., Van Baaren, J., Vernon, P. and Bolvin, G. 2007. Impact of streme temperature on parasitoids in a climate change perspective Ann. Rev. Entomol. 52: 107-26.

25) Hibberd JM, Whitbread R and Farrar JF 1996. Effect of elevated concentrations of $\mathrm{CO}_{2}$ on infection of barley by Erysiphe graminis. Physiol. Mol. Plant Pathol. 48: 37-53. 


\section{International Journal of Advanced Multidisciplinary Scientific Research (IJAMSR) ISSN:2581-4281}

26) Hunter, M.D. 2001. Effects of elevated atmospheric carbon dioxide on insect-plant interactions. Agric. For. Entomol. 3: 153-159.

27) Hyre, R.A. 1954. Progress in forecasting late blight in potato and tomato Plant disease reporter 38, 245-253

28) IARI, News.2008. Brown plant hopper outbreak in rice, $24,1-2$

29) IRRI, News.2009. Pest outbreaks in India Rice today, 6 www.ricenews.irri.org

30) Joshi, S. and Viraktamath, C.A. 2004. The sugarcane woolly aphid, Ceratovacuna lanigera Zehntner (Hemiptera: Aphididae): its biology, pest status and control. Curr. Sci., 87, 307-316

31) Jwa NS and Walling LL 2001. Influence of elevated $\mathrm{CO}_{2}$ concentration on disease development in tomato. New Phytologist, 149: 509-518.

32) Karnosky DF, Percy KE and Xiang BX 2002. Interacting elevated $\mathrm{CO}_{2}$ and tropospheric $\mathrm{O}_{3}$ predisposes aspen (Populus tremuloides Michx.) to infection by rust (Melampsora medusae f. sp tremuloidae). Global Change Biol. 8: 329-338.

33) Kobayashi T, Ishiguro K, Nakajima T, Kim HY, Okada M and Kobayashi K 2006. Effects of elevated atmospheric $\mathrm{CO}_{2}$ concentration on the infection of rice blast and sheath blight. Phytopathology, 96: 425-431.

34) Kuchlein, J.H. and Ellis, W.N.1997. Climateinduced changes in the microlepidoptera fauna of the Netherlands and the implications for nature conservation. J. Insect conserv. 1, 73-80

35) Lacey, J., Bateman, G.L. and Mirocha, C.J. 1999. Effects of infection time and moisture on development of ear blight and deoxynivalenol production by Fusarium spp. in wheat. Annals of Applied biology 134, 277-283.

36) Lake JA and Wade RN 2009. Plant-pathogen interactions and elevated $\mathrm{CO}_{2}$ : morphological changes in favour of pathogens. J. Exp. Bot.60(11): 3123-3131

37) Lingappa,S., Yelshetty, S. and Venkatesh, H. 2003. Weather Based Forewarning System for the Pest and Disease Management Jour. Ind. Soc. Ag. Statistics 56( I). 2003: 88-99

38) Matros A, Amme S, Kettig B, Buck-Sorlin GH, Sonnewald U and Mock HP 2006. Growth at elevated $\mathrm{CO} 2$ concentrations leads to modified profiles of secondary metabolites in tobacco cv. SamsunNN and to increased resistance against infection with potato virus Y. Plant Cell Environ. 29: 126-137.

39) Mcelrone AJ, Hamilton JG, Krafnick AJ, Aldea M, Knepp RG and De Lucia EH 2010. Combined effects of elevated $\mathrm{CO}_{2}$ and natural climatic variation on leaf spot diseases of redbud and sweetgum trees. Environ. Pollut. 158: 108-114.

40) Mina, U and Sinha, P. 2008. Enviro News Int. Soc. of Environmental Botanists Vol. 14 No. 4 October

41) Osbrink, W.L.A., Trumple, J.T. and Wagner, R.E.1987. Host suitability of Phaseolu lunata for Trichoplusiani (Lepidoptora:Noctuidae) in controlled carbon dioxide atmosphere. Envi. Entomol. 16: 639-44.

42) Pande, S., Desai, S and Sharma, M.2010.National Symposium on Climate Change and Rainfed Agriculture, February, 1820, 2010, CRIDA, Hyderabad, India

43) Pangga IB, Chakraborty S and Yates D 2004 Canopy size and induced resistance in Stylosanthes scabra determine Anthracnose severity at high $\mathrm{CO}_{2}$. Phytopathology, 94: 221227.

44) Parmesan, C. 2006. Ecological and evolutionary response to recent climate change Ann. Rev. Ecol.Syst. 37: 637-63.

45) Parmesan, C., Yohe, G. 2003. A globally coherent fingerprint of climate change impacts across natural systems. Nature, 421, 37- 42

46) Phytophthora: its biology, taxonomy, ecology and pathology (D.C. Erwin, S. Bartnicki-Garcia \& P.H. Tsao, eds.), The American Phytopathological Society, St. Paul, Minnesota.

47) Porter, J.H., Parry, M.L. and Carter, T.R.1991. The potential effects of climatic change on agricultural insect-pests, Agric. For.Meteorol., 57, 221-40

48) Pugh, G.W., Johann, H. and Dickson, J.G. 1933. Factors affecting infection of wheat heads by Gibberella saubinetii. Journal of Agricultural Research 46, 771-797.

49) Regnier, J. 1983. An oviposition model for the spruce budworm, choristoneura fumiferana (Lepidoptera: Tortricidae). Can Entomol. 115: 1371-82.

50) Roth, S.K. and Lindroth, R.L. 1995. Elevated atmospheric $\mathrm{CO}_{2}$ : Effect on photochemistry, insect performance and insect parasitoid interactions. Global Change Biol. 1: 173-82. 


\section{International Journal of Advanced Multidisciplinary Scientific Research (IJAMSR) ISSN:2581-4281}

51) Runion, GB., Prior, SA., Rogers, $\mathrm{HH}$ and Mitchell, RJ. 2010. Effects of elevated atmospheric $\mathrm{CO}_{2}$ on two southern forest diseases. New Forests, 39: 275-285

52) Sharma, H.C., Dhillon, M.K., Kibuka, J. and Mukuru, S, Z. 2005. Plant defense responses to sorghum spotted stem borer, Chilo partellus under irrigated and drought conditions. International Sorghum and Millets Newsletter, 46, 49-52

53) Sharma, H.C., Srivastava, C.P., Durairaj, C. and Gowda, C.L.L.2010. Pest management in grain legumes and climate change. In Climate Change and Management of Cool Season Grain Legume Crops (eds.Yadav, S.S., McNeil, D.L. Redden, R, and Patil, S.A,), Business Media, Springer Science, Dordrecht, The Netherlands, pp. 115-140.

54) Shin JW and Yun SC 2010. $\mathrm{CO}_{2}$ and Temperature effects on the Incidence of Four Major Chili Pepper Diseases. Plant Pathol. J. 26(2): 178-184.

55) Smith, L.P. 1956. Potato blight forecasting by 90 percent humidity criteria Plant pathology 5

56) Srikanth, J. 2007. World and Indian scenario of sugarcane woolly aphid In Woolly Aphid Management in Sugarcane (eds. Mukunthan, N., Srikanth, J., Singaravelu, B., Rajula Shanthy, T., Thiagarajan, R. and Puthira Prathap, D.), Extension Publication, Sugarcane Breeding Institute, Coimbatore, 154, 1-12

57) Stacey, D.A. and Fellows, M.D.E. 2002. Influence of temperature on pea aphid A cythosiphan pisum (hemiptera: aphidae) resistence to natural enemy attack. Bull. Entomol. Res. 92: 351-7.

58) Strengbom J and Reich PB 2006. Elevated $\left[\mathrm{CO}_{2}\right]$ and increased $\mathrm{N}$ supply reduce leaf disease and related photosynthetic impacts on Solidago rigida. Oecologia, 149: 519-525.

59) Tanwar, R.K., Jeyakumar P. and Vennila, S.2010. Papaya mealybug and its management strategies Technical Bulletin 22, National Centre for Integrated Pest Management, New Delhi,

60) Thomas, C.D., Cameran, A. and Green R.E. 2004. Extinction risk from climate change. Nature 427: 145-8.

61) Tiedemann AV and Firsching KH 2000. Interactive effects of elevated ozone and carbon dioxide on growth and yield of leaf rustinfected versus non-infected wheat. Environ. Pollut. 108: 357-363
62) Trumble, John. and Butler, Casey. 2009. Climate change will exacerbate California's.Insect pest

63) Yamamura, K. and Kiritani, K. 1998. A simple method to estimate the potential increase in the number of generations under global warming in temperate zones. Appl. Entomology Zool. 33: 289- 298. 